Canadian Studies in Population 43, no. 1-2 (2016): 48-77.

\title{
Trends, patterns, and differentials in Canadian mortality over nearly a century (1921-2011)
}

\author{
Robert Bourbeau ${ }^{1}$ \\ Nadine Ouellette
}

\begin{abstract}
In the past 90 years, remarkable progress has been made in substantially improving survival and longevity in Canada, establishing it among today's group of very low mortality countries. We use several demographic indicators of all-cause and cause-specific mortality to illustrate the nature of these major advances throughout the lifespan. Reviewing the literature on trends in Canadian mortality, we also uncover various challenges for the decades to come. Reducing or even eliminating important disparities in mortality that persist with regards to geography and several socioeconomic factors is one of the greatest challenges ahead.
\end{abstract}

Keywords: mortality, longevity, health, trends, Canada.

\section{Résumé}

Au cours des 90 dernières années, le Canada a connu des progrès remarquables en matière de survie et de longévité, ce qui le situe parmi le groupe de pays à très faible mortalité. Plusieurs indicateurs démographiques de mortalité générale et par cause sont utilisés pour montrer la nature de ces avancées à tous les âges de la vie. La revue des connaissances sur la mortalité canadienne a aussi permis de mettre en relief les défis des prochaines décennies. Réduire, voire supprimer les différences importantes de mortalité qui persistent selon la région et selon plusieurs caractéristiques socioéconomiques représente un de ces principaux défis.

Mots-clés : mortalité, longévité, santé, tendances, Canada.

\section{Introduction}

Canada ranks among the wealthiest and most developed nations in the world according to various socioeconomic indicators such as the Gross Domestic Product and the Human Development Index. It is also known to be a very egalitarian society in terms of resource redistribution and access to public services. Canadians benefit from universal income protection programs at age 65 years, for instance, and a universal healthcare system throughout their lives, administered by the country's ten provinces and three territories. The healthcare system is publicly funded and the governments contribute about 70 per cent of total healthcare costs (OECD 2014).

1. Co-lead authors: Robert Bourbeau (corresponding author), Département de démographie, Université de Montréal, Pavillon Lionel-Groulx, 3150 rue Jean-Brillant, Montréal QC H3T 1N8, e-mail: robert.bourbeau@ umontreal.ca; and Nadine Ouellette, Institut national d'études démographiques (INED), Paris. 
The majority of developed nations have experienced several profound demographic changes over the last century-notably, an important decline in fertility rates paired with a substantial reduction of mortality, due in part to the changing nature of leading causes of death. In Canada, the total fertility rate was 3.5 children per woman in 1921 and fell to 1.61 in 2011 (Wadhera and Strachan 1993a; Statistics Canada 2013a). Life expectancy at birth for both sexes combined rose, from 57.0 years in 1921 to 81.7 in 2011 (Canadian Human Mortality Database 2014). Migration has also become an increasingly important contributor to population growth over this time period. Whereas less than 25 per cent of the Canadian population growth was due to migratory increase (i.e., surplus of in-migrants over outmigrants) during 1951-56, this share climbed to almost 70 per cent for 2006-11. Immigrants thus make up a significant portion of the Canadian population and the latest figures reveal that 20.6 per cent of current residents are foreign-born (Statistics Canada 2013a). The large immigrant population likely bolsters Canada's health indicators, partly because immigrants are admitted to Canada upon a medical examination. They are also often selected on characteristics that are associated with better health (e.g., higher education and income), and they sometimes have firmly established advantageous cultural behaviours (e.g., healthy diets and lifestyles). This is typically referred to as the "healthy immigrant effect" (Trovato 1985; Bourbeau 2002a; Omariba et al. 2014).

In the present article, we are mainly interested in the tremendous transformation that Canadalike many other developed countries - underwent with regards to its population's health and longevity over nearly a century. There is a fairly large body of literature discussing and documenting various aspects of these changes. Of particular interest here are studies that:

1. examined trends over varying lengths of time (Bourbeau and Légaré 1982; Nagnur 1986; Adams 1990; Nagnur and Nagrodski 1990; Baxter and Ramlo 1998; Manuel and Hockin 2000; Bourbeau 2002b; Beaujot and Kerr 2003; Henripin 2003; Martel and Bourbeau 2003; Prud'homme 2007; Barbieri and Ouellette 2012; Decady and Greenberg 2014);

2. carried out differential or comparative analyses by sex, province, immigrant status, income level, or educational attainment (Wilkins 1980; Trovato 1985, 1993, 2007; Trovato and Lalu 1995, 2001; Nault 1997; Andreev 2000; Bourbeau 2002a; Prud'homme 2007; Wilkins et al. 2008; Zanfongnon 2008; Pampalon 2009a, 2009b, 2009c; Omariba et al. 2014);

3. focused on the epidemiology of population change through cause-of-death analyses (Bah and Rajulton 1991; Bourbeau 2002b; Lussier et al. 2008; Bergeron-Boucher 2012);

4. investigated changes in healthy life expectancy (for an overview see Bourbeau et al. 2011; Mandich and Margolis 2014).

These studies show that the health and longevity evolution in the past 90 years is characterized notably by large declines in infant mortality, a substantial increase in life expectancy, important variations of sex differences in average length of life, improved survival at old and very old ages, rectangularization of the survival curve, changing causes of death, and a reduction of geographic disparities in mortality between Canadian provinces.

The present article is principally intended as a historical overview of trends and patterns of mortality in Canada, and shows the country's spectacular progress in the control of mortality and efforts to improve health. We achieve this objective by bringing together present-day knowledge and research findings to better define future challenges. The health and longevity advances are described using basic or more sophisticated demographic indicators, which will be introduced along the way. The paper begins with an overview of our data sources. We then examine declines in mortality over time that led to a remarkable increase in survival, followed by a section focussing on the changing age distribution of deaths and its consequences. Addressed next are some new challenges in dealing 
with survival progress: changes in leading causes of death, emergence of centenarians, healthy life expectancy, obesity, geographic disparities in mortality, and socioeconomic inequalities in health. We conclude by discussing the future of mortality in Canada as compared to other developed countries.

\section{Data sources}

Canada's long tradition of registering births, marriages, and deaths is largely attributable to the religious denomination of a significant share of its population. Demographic events pertaining to French-Canadians - which formed a homogeneously Catholic society-were systematically registered by the religious authorities upon their arrival to Canada during the first half of the 17 th century. Nearly all baptisms, marriages, and burials of Catholics were thus meticulously registered, making it possible to study demographic trends from a long-term perspective. The major task of reconstituting these trajectories was undertaken in the 1960s by the Programme de recherche en démographie historique at the Université de Montréal (Charbonneau et al. 1972). Another share of Canada's population at the time consisted of British-born individuals, most of which were Protestant. While Protestant societies also registered demographic events, the registration was not as systematic as for the French-Canadians. For this reason, the data used in the present article begin only much later (early 1920s). Our study relies on several sources of data: Canada's vital statistics system, the Census, and health surveys.

For Canada as a whole, reliable data on all-cause mortality are available from 1921, when the government established vital statistics registration. While each of the ten provincial and three territorial administrations are in charge of collecting these data, Statistics Canada is responsible for assembling them at the national level. Statistics Canada also produces annual population estimates by age and sex for Canada, provinces, and territories. ${ }^{2}$ The recently revised methodology for these estimates gives more accurate population counts, which serve as denominators for the rates calculated in this article (Statistics Canada 2014a). It should be noted that all these data are also available in the Canadian Human Mortality Database (www.bdlc.umontreal.ca), established by demographers at the Universite de Montréal in collaboration with the Human Mortality Database (www.mortality.org) project team.

Cause-specific mortality data are based on information listed on death certificates by qualified physicians - in the province or territory where the event took place — and according to WHO's International classification of diseases (ICD); the classification is subject to revision, occurring roughly once every ten years since 1900. In the present paper, our analyses of cause-specific mortality trends start in 1950 and end in 2011, covering five revisions of the ICD. ${ }^{3}$ The transition from one ICD revision to the next is likely to create major discontinuities in cause-specific mortality trends over time, especially for highly specific causes of death, while the use of broad disease categories is less problematic. We focus here on cause-of-death groupings that had considerable impact on survival in Canada over the past 60 years: heart diseases, cerebrovascular diseases, smoking-related malignant neoplasms, ${ }^{4}$ all other types of malignant neoplasms, infectious and parasitic diseases, respiratory diseases, and external causes of death. The concordance table used for bridging the five revisions of the ICD is provided in the appendix.

2. For 1921-70, see Catalogue no. 91-512, and after 1970, see CANSIM database, Table 051-0001.

3. Although data on causes of death are available since 1921 in Canada, the quality of these data for the 192149 period is not sufficient to get a precise picture of trends in mortality by cause. Moreover, the construction of coherent series of deaths by cause is challenging over very long periods of time, because a greater number of successive revisions of the ICD need to be bridged. For these reasons, we have focused our analysis on cause-of-death data from 1950 forward.

4. Our category of smoking-related malignant neoplasms includes most cancers of the respiratory and upper digestive tracts, namely cancers of the lip, oral cavity, pharynx, oesophagus, larynx, trachea, bronchus, and lung, as proposed by Ouellette et al. (2014). 
Canadian data are known to be of very good quality, and it is widely accepted that they can be used to portray mortality changes accurately. As for the state of health of the Canadian population, the data presented here are taken from two surveys on the prevalence of diseases, disabilities, and other health-related conditions, namely the National Population Health Survey and the Canadian Community Health Survey. The surveys began at the end of the 1970s, and the data have been collected at irregular intervals ever since.

\section{Changes in mortality over time: A remarkable progress in survival}

\section{Death rate trends by age and sex}

The evolution of mortality in Canada, both in terms of level and age-pattern, is reflected by a set of mortality rates by age, sex, and calendar year. Using data on death counts and population estimates, we computed death rates by single years of age and sex for each calendar year from 1921 to 2011. These sex-specific death rates by age and time are presented on shaded contour maps, also known as Lexis surface maps in demography and specifically referred to as mortality surfaces in the context of mortality (see Figure 1). The surfaces summarize a considerable volume of data on a single graph and are very useful for looking at long-range mortality trends. They also provide an excellent exploratory tool for detecting age, period, and cohort effects (Caselli et al. 1985). The scale on the right-hand side of Figure 1 indicates how death rates were partitioned into nine groups, each with its own colour. On the surface, death rates belonging to a given group are assigned the same colour.

Surfaces in Figure 1 reveal noticeable changes in colour composition as time unfolds-there are fewer red and orange zones and progressively more green and blue zones-which shows the general decline in death rates since 1921. The pace of the decline, however, varies by age and sex.
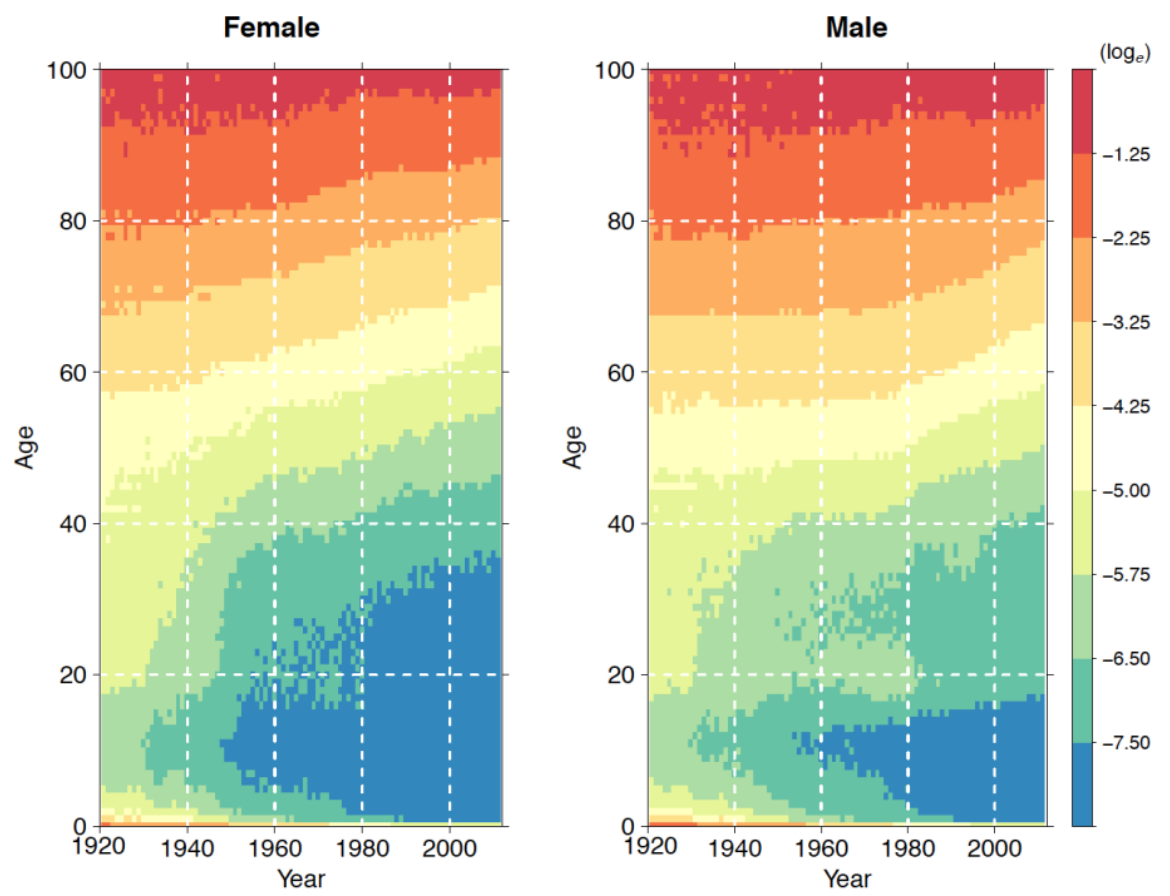

Figure 1. Lexis surface maps of observed death rates (logarithmic scale) for females and males in Canada, ages 0 to 100, 1921-2011.

Source: Canadian Human Mortality Database, 2014. 
We first notice a clear fall in infant and juvenile mortality, as evident at the bottom of female and male surfaces. Death rates at these early ages reached very low levels in Canada (less than 10 per thousand) from the mid-1980s onwards. Mortality among young adult females is driven by changes in maternal mortality, which gradually disappears, giving way to deaths due to external causes (e.g., accidents), but at levels well below that of males - shown in the dominance of blue rather than turquoise zones at ages 15-49 after the 1960s on the female surface. The mortality of young adult males is indeed characterized by a significant share of deaths due to accidents and suicides, still perceptible up to 2011, although substantial declines have occurred since the end of the 1970s. Among older adults and at very old ages, the onset of mortality decrease was recorded earlier for females than for males-around the 1940s and 1950s, where yellow and orange diagonal stripes (rather than horizontal) start appearing on the female surface. A similar decline begins only in the 1970s among the males.

\section{Annual rates of mortality change by age and sex}

To better identify the specificities of changes in mortality in Canada since 1921, we computed rates of mortality change by age and time, and then graphed these on a Lexis surface map. Using data for single years of age and single calendar years, we calculated annual rates of change of mortality $\rho(x, t)=-\log _{e}\left(\frac{m(x, t+1)}{m(x, t)}\right)$, where $m(x, t)$ is the death rate for the age interval $[x, x+1[$ during calendar year $\mathrm{t}$. Values of $\rho$ greater/smaller than zero indicate that death rates declined/increased between year $t$ and $t+1$ at age $x$. The indicator was first proposed by Kannisto (1994) and recently taken up by Rau and colleagues (2013) to detect predominant mortality dynamics, with a particular interest in uncovering age, period, and cohort effects.
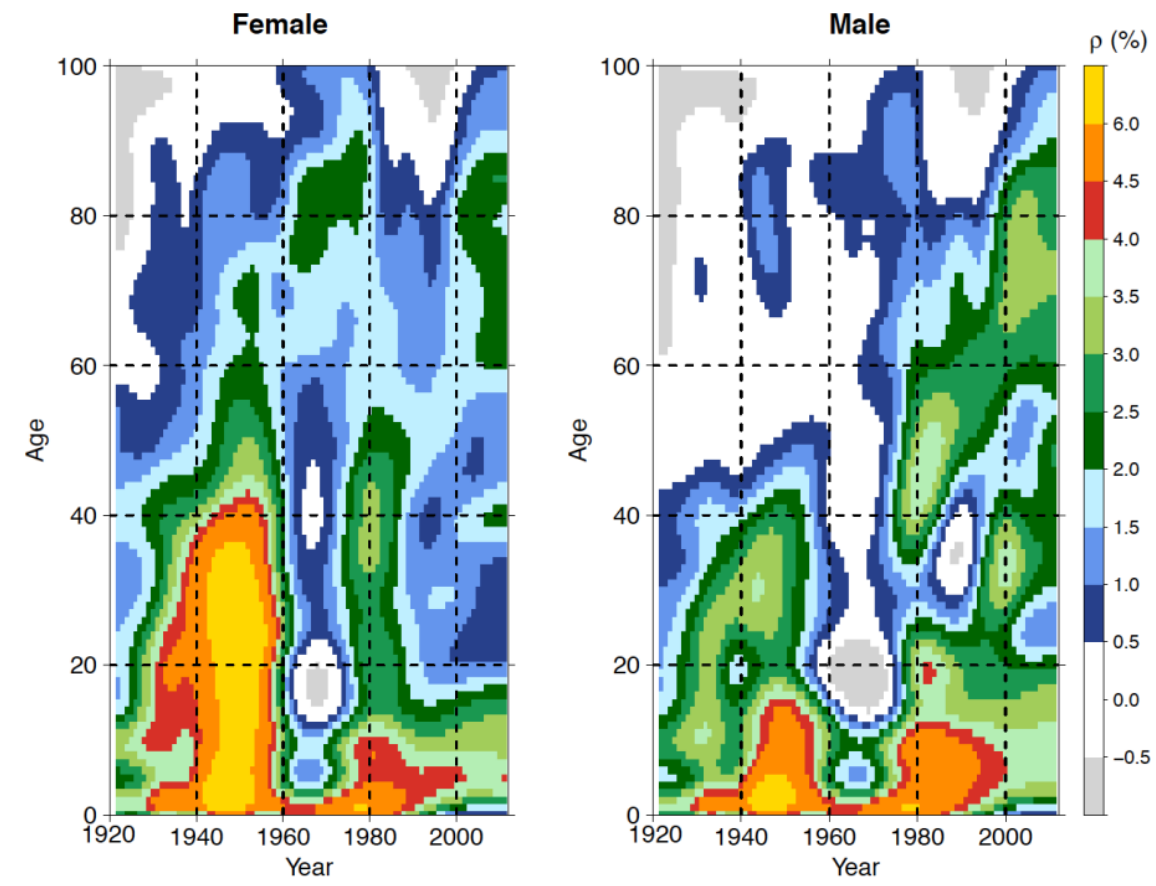

Figure 2. Lexis surface maps of annual rates of mortality change for females and males in Canada, ages 0 to 100, 1921-2011.

Note: Prior to computing $\rho$, we smoothed death rates over ages and calendar years simultaneously with a P-spline approach based on penalised Poisson likelihood (Eilers and Marx 1996), using the R package "MortalitySmooth" (Camarda 2012).

Source: Author's calculations based on the Canadian Human Mortality Database, 2014. 
Figure 2 presents annual rates of mortality change for Canadian females and males separately. The scale on the right-hand side indicates that minor changes $(\rho \epsilon]-0.5 \%, 0.5 \%])$ are shown in white on the surfaces, slight mortality improvements $(\rho \epsilon] 0.5 \%, 2.0 \%])$ in shades of blue, moderate improvements $(\rho \epsilon] 2.0 \%, 4.0 \%])$ in shades of green, and strong improvements $(\rho>4.0 \%)$ in red to yellow shades. Gray is used for worsening mortality conditions $(\rho \leq-0.5 \%)$.

A first observation is that values of $\rho$ can vary substantially from year to year and from age to age, thus confirming that mortality decline is not uniform across time and over the life course. Annual rates of mortality decline can be greater than 6 per cent but a few episodes of slight mortality increase have also been recorded. For instance, the mortality of young male adults aged 15-24 increased during the 1960s — see the gray round-shaped zone-because of a rise in death rates, notably due to vehicle and traffic injuries. The greatest mortality improvements-red to yellow shaded zones-concerned infants, children, adolescents, and females of childbearing ages.

Moreover, the surfaces show more convincingly than above (Figure 1) that female mortality progress among older adults and at very old ages preceded that of males. For the latter, slight mortality improvements remained scarce, whereas moderate improvements were inexistent at these ages prior to the onset of the cardiovascular revolution around $1970 .{ }^{5} \mathrm{It}$ is worth noting that during the 1960s, mortality decline stalled among males in Canada, as in many other low-mortality countries. Figure 2 suggests that period effects were the main forces underlying this trend, because it affected many age groups (ages 30-80) simultaneously. In recent years, progress was mostly recorded above age 60 , where the vast majority of deaths occur. This is particularly true for males, where rates of mortality improvements range from 2 to 3.5 per cent.

\section{Sex-specific life expectancies at age $0,65,75$, and 85}

The age-specific death rates illustrated on Figure 1 can be summarized by a measure of central tendency, such as life expectancy at birth $\left(\mathrm{e}_{0}\right)$. Over nearly a century in Canada, $\mathrm{e}_{0}$ increased by 25.5 years for females, growing from 58.2 in 1921 to 83.7 years in 2011, and by 23.5 years for males, growing from 56.0 to 79.5 years (Figure 3A). These correspond to gains of about 2.8 and 2.6 years per decade on average, respectively (roughly 3 months per year). Still, the pace of increase in $\mathrm{e}_{0}$ varied greatly by sex and by period. Among females, the pace slowed down gradually with time. For males, the progress was slowest during 1955-70, but the rapid pace of increase resumed afterward, to meet and even exceed that of females from 1980 onwards. The trend is likely to continue over the next two decades, partly because of diverging smoking-related cancer patterns between the sexes (Pampel 2002; Preston et al. 2014).

As survival to higher ages increases, measures of life expectancies at older ages (e.g., $\mathrm{e}_{65}, \mathrm{e}_{75}$, and $\mathrm{e}_{85}$ ) are of undeniable interest. Figure $3 \mathrm{~B}$ shows that in Canada, $\mathrm{e}_{65}$ started to rise meaningfully during the 1940s among females, $\mathrm{e}_{75}$ during the 1950 s, and $\mathrm{e}_{85}$ during the 1970 s. For males, these old-age life expectancies stagnated during many years, showing little to no progress before the 1970s, but eventually increased rapidly.

According to data for the year 2011, Canadian women aged 65 could expect to live to age 86.8 and their male counterparts to age 83.9. These ages at death correspond to lowest possible estimates because they do not include any expected improvement to future old-age mortality.

5. The revolution refers to a broad range of innovations that resulted in widespread and rapid reductions in cardiovascular disease morbidity and mortality. It includes innovative therapeutic and surgical procedures, improvements in healthcare systems (emergency ambulance services, notably), as well as changes in individual behaviour (physical exercise, diet, and tobacco consumption, in particular) (Caselli et al. 2002). 
A. Life expectancy at age $0\left(\mathrm{e}_{0}\right)$

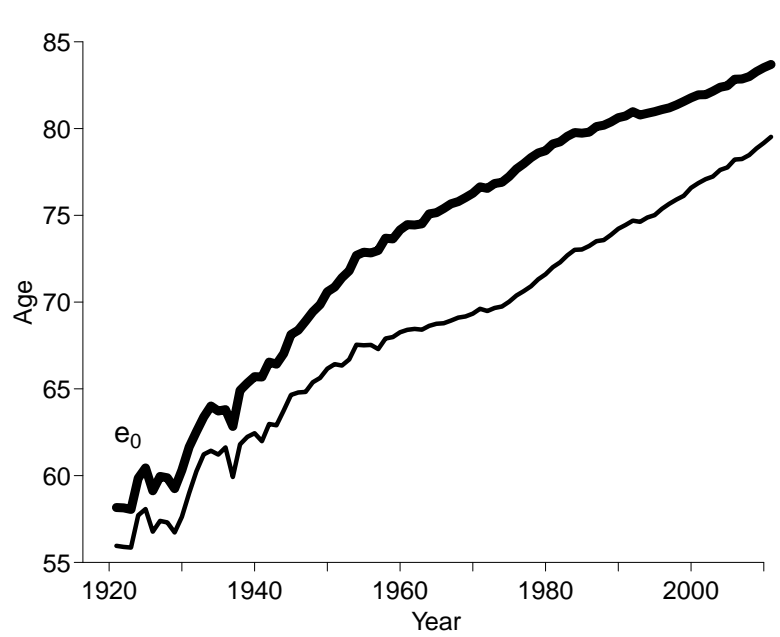

B. Remaining life expectancies at age $65\left(\mathrm{e}_{65}\right), 75\left(\mathrm{e}_{75}\right)$, and $85\left(\mathrm{e}_{85}\right)$

Figure 3. Life expectancy at birth and remaining life expectancies at age 65, 75, and 85 for females (thick lines) and males (thin lines) in Canada, 1921-2011.

Source: Canadian Human Mortality Database, 2014.

\section{Narrowing sex differentials in mortality}

In the last nine decades, the sex gap in $\mathrm{e}_{0}$ (female minus male) in Canada followed a trend comparable to that of most current low-mortality countries. Up until the late 1970s, the gap grew substantially, rising from 2.2 years in 1921 to 7.4 in 1978 (Figure 4), as female $\mathrm{e}_{0}$ increased more rapidly than that of men (Figure 3A). Afterwards, however, $\mathrm{e}_{0}$ rose faster for men, and the sex gap in $\mathrm{e}_{0}$ narrowed unabated to 4.2 years in 2011.

The accelerated widening of the sex gap in $\mathrm{e}_{0}$ in Canada between the mid-1940s and the late 1970s was in large part due to less favourable trends in male mortality from cardiovascular diseases (heart diseases, in particular) and malignant neoplasms (mainly lung and other types of cancers closely related to smoking) (Waldron 1993; Meslé 2004). The surge in male tobacco consumption contributed significantly to these trends, both from a period (Peto et al. 2005; Preston et al. 2011) and a cohort perspective (Preston and Wang 2006). The narrowing of the gap since the 1978 downturn is due mostly to the reduction of sex differences in cardiovascular mortality, a trend often associated to females progressively adopting social behaviours more similar to those of males (notably in terms of employment, smoking, and alcohol consumption) (Waldron 1993; Trovato and Lalu 1995; Pampel 2002; Meslé 2004; Trovato and Heyen 2006; Trovato 2007). Males have also become increasingly aware of the importance of managing their health (e.g., more frequent doctor visits, routine health check-ups from an earlier age), something that females had understood much earlier (Meslé 2013). While both sexes made substantial progress in cardiovascular mortality since the downturn, males have enjoyed greater gains as they started at a considerable disadvantage (see Figure 10 in the "Causes of death" section below for more details). Sex differences in smokingrelated cancer mortality have also narrowed in the past 30 years, with a continuous increase for females (but slowing markedly since the early 1990s) and a rapid decrease among males, due to very distinct patterns in tobacco consumption history. 


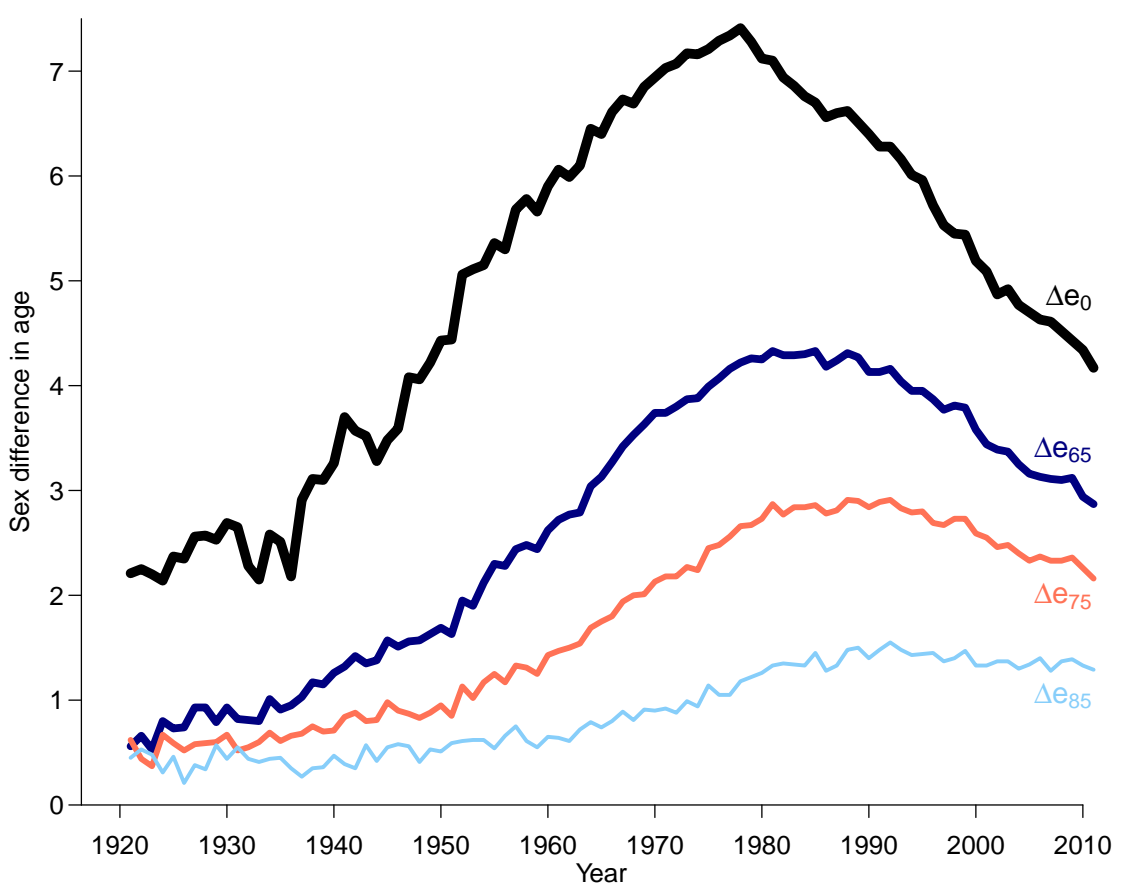

Figure 4. Sex difference (female minus male) in life expectancy at birth $\left(\Delta e_{0}\right)$, at age $65\left(\Delta e_{65}\right)$, at age $75\left(\Delta e_{75}\right)$, and at age $85\left(\Delta e_{85}\right)$ in Canada, 1921-2011.

Source: Author's calculations based on the Canadian Human Mortality Database, 2014.

Sex differences (female minus male) in life expectancy at older ages such as 65, 75, and 85 are also illustrated in Figure 4. The smaller differences in these life expectancies than in $\mathrm{e}_{0}$ were expected because sex differentials in $\mathrm{e}_{0}$ reflect mortality at all ages, whereas sex differences in $\mathrm{e}_{65}, \mathrm{e}_{75}$, and $\mathrm{e}_{85}$ depend on old-age mortality only. Figure 4 also shows that the four measures of differences between females and males differ not only in levels (i.e., in years) but also in trends. Downturns can be seen for the sex gaps in $\mathrm{e}_{65}, \mathrm{e}_{75}$, and $\mathrm{e}_{85}$, but occurred later and were less pronounced than for $\mathrm{e}_{0}$. In particular, the downturn for $\mathrm{e}_{85}$ was fairly recent (around 1990) and very modest. Further investigation is needed to determine the specific causes of death responsible for these differences, and to speculate on future trends.

\section{Excess male mortality by age}

Figure 5 shows in greater detail the change over time in excess male mortality, using male-tofemale ratios of age-specific death rates. From 1921 until the early 1940s, maternal mortality gave rise to an episode of excess female mortality in Canada at childbearing ages, depicted by a dark blue zone on the mortality ratio surface. Afterwards, male mortality increased slightly for some periods, as seen earlier in Figure 2, but essentially male mortality has decreased less rapidly than for females. Figure 5 shows that excess male mortality has been particularly high for young adults, because of accidents and violent deaths at ages 20-40, as well as at ages 55-70, where the death toll from cardiovascular diseases was substantial.

Excess male mortality remains an important aspect of Canadian mortality studies. But nowadays, the excess remains most prevalent at ages where the level of mortality is relatively low-notably between the ages of 18 and 30 years — and thus weighs less heavily on the overall sex gap in mortality. 


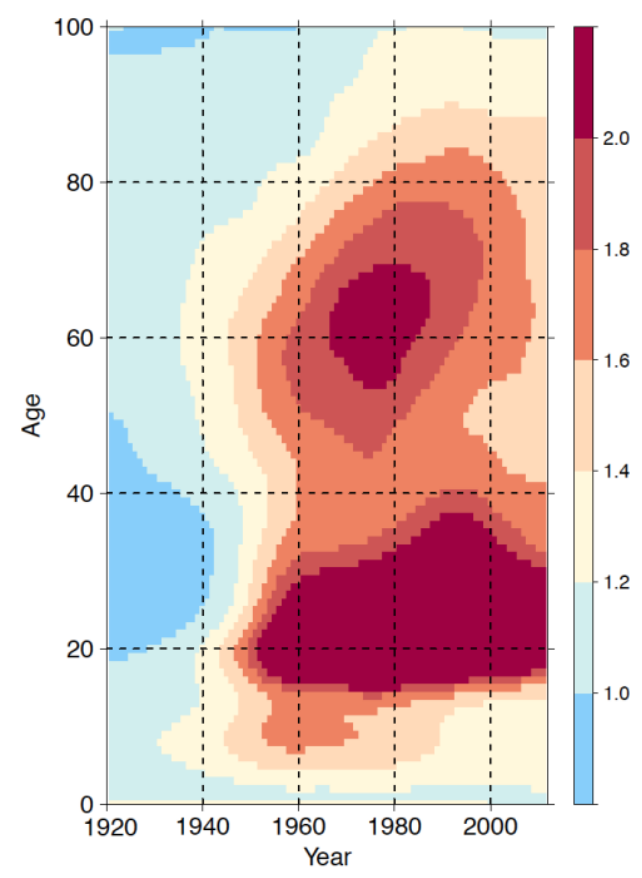

Figure 5. Lexis surface map of male-to-female sex ratio of age-specific death rates in Canada, ages 0 to 100, 1921-2011.

Source: Author's calculations based on the Canadian Human Mortality Database, 2014.

Note: Prior to computing the male-to-female sex ratio of age-specific death rates, we smoothed the death rates over ages and calendar years simultaneously for each sex with a P-spline approach based on penalised Poisson likelihood (Eilers and Marx 1996), using the R package "MortalitySmooth" (Camarda 2012).

\section{Infant mortality: The growing importance of the first 7 days after birth}

The infant mortality rate has long been regarded as an important and sensitive indicator of a community's sanitary conditions, as well as its socioeconomic status. To this end, the spectacular decline in infant mortality over the past 85 years is one of the most significant achievements of Canadian society. Mortality during the first year of life was reduced more than 20-fold since 1926 in Canada, falling from 100 infant deaths per 1,000 to less than 5 per 1,000 in 2011 (Figure 6).

Progress is slower since the early 1990s because it is increasingly difficult to reduce mortality, due primarily to so-called endogeneous causes (e.g., congenital anomalies or birth defects and perinatal conditions). Generally speaking, as the level of infant mortality declines over time, deaths tend to be progressively concentrated near birth, thus reflecting a shift from predominantly infectious and parasitic diseases to causes predominantly linked to the vicissitudes of nature, genetics, or pregnancy-related traumas. Deaths occurring during the neonatal period-the first 4 weeks after birth-accounted for nearly half (47 per cent) of all infant deaths in Canada in 1926; the proportion grew to 75 per cent in 2011. The increase is even more pronounced for deaths in the early neonatal period - the first 7 days following birth—as the share rose from 33 per cent to 62 per cent over the same timespan. 


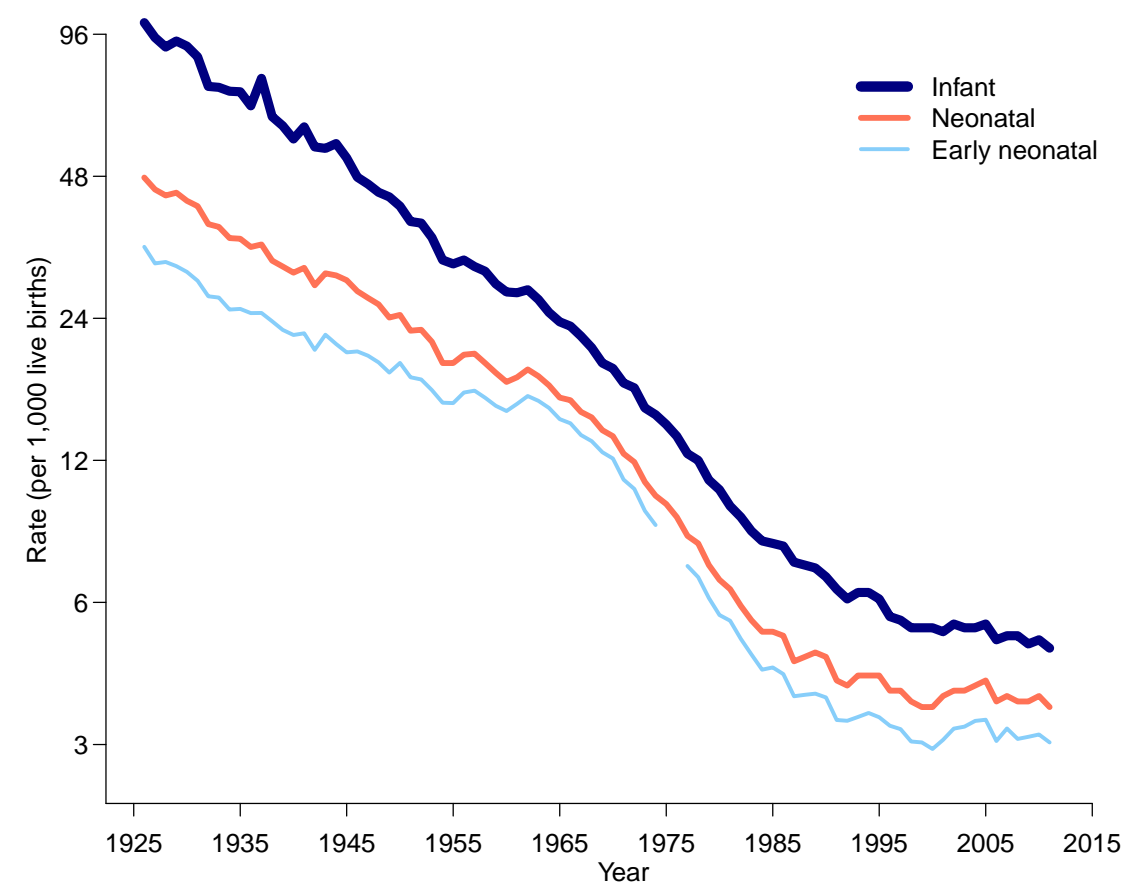

Figure 6. Infant, neonatal, and early neonatal mortality rates (log scale) for both sexes combined, Canada, 1926-2011.

Sources: For infant and neonatal mortality, 1926-90: Wadhera and Strachan (1993b, Tables 2b and 6), 1991-2009: Statistics Canada, CANSIM database (Table 102-0507); for early neonatal mortality, 1926-90: authors' calculations based on Wadhera and Strachan (1993b, Table 6) and the Canadian Human Mortality Database (2014), 19912011: authors' calculations based on Statistics Canada, CANSIM database (Tables $102-0508$ and 102-4501).

Note: The early neonatal mortality rates for calendar years 1975 and 1976 are missing because the number of early neonatal deaths is not available.

Medical advances, paired with economic growth and a well-targeted perinatal public policy (Canadian Perinatal Surveillance System, or CPSS, of the Public Health Agency of Canada) have played an important role in the great decline in infant mortality since 1926. Current levels of infant mortality in Canada, however, continue to be above those of several European countries, as well as Japan, in some instances by as much as 50 per cent.

\section{The changing age distribution of deaths}

\section{Compression of mortality and the rectangularization of survival curves}

The above sections of this paper have highlighted the great mortality decline that occurred in Canada during the 20th century. As in most high-income countries, death rates in Canada have fallen more sharply (in relative terms) at younger rather than at older ages. The age distribution of deaths has thus shifted towards more advanced ages and become less dispersed, a phenomenon commonly referred to as compression of mortality. Moreover, the shape of the survival curve has become more rectangular, known as the rectangularization of the survival curve. These two intuitive concepts, dating back seemingly to the 1920s (Pearl 1923) and which were later given more formal definitions, can be casually inspected from graphical illustrations of the distribution of deaths and the survival curve for a few selected periods. 
There is evidence of mortality compression whenever, over time, a rising proportion of deaths occur within a progressively restricted age interval. For instance, Figure 7A shows that as the periods between 1921-24 and 2005-09 unfolded, the distribution of deaths of Canadian females became increasingly concentrated into a narrow range of ages while it shifted to the right. The picture for Canadian males (not shown here) is similar, although the compression of mortality and the shift towards older ages are not as significant.

The corresponding set of changes in terms of survival curves is shown in Figure 7B, which illustrates how Canadian females underwent their rectangularization process. We see that for the 1921-24 period, the proportion of survivors falls sharply during the first years of life because of the high infant and child mortality. Afterwards, the survival curve first levels off somewhat, then declines slowly until about age 60, before dropping off rapidly into advanced old age. Compared to the shape of the 1921-24 survival curve, the one for 1950-54 is more rectangular. Indeed, by 1950-54 we already observe progress in reducing mortality among young children. The survival curve then drops gradually until about age 65 , after which the proportion of survivors falls rapidly. The evolution of the survival curves through to 2005-09 is more of the same, except that the curves become slightly closer to a true rectangle.

To move beyond visual inspection and therefore allow for more detailed comparisons over time and space, scholars have proposed a number of measures for either the variability of the age distribution of deaths or the rectangularity of the survival curve (for an overview and critique of the measures, see Wilmoth and Horiuchi 1999; Cheung et al. 2005; van Raalte and Caswell 2013). Nagnur (1986) was the first to look closely at the phenomenon of rectangularization in Canada. Using the life table entropy - a measure of rectangularity proposed by Keyfitz- he confirmed that the rectangularization process had in fact been ongoing for both Canadian males and females since the early 1920s. For the province of Quebec more specifically, Martel and Bourbeau (2003) used various measures to show that rectangularization of the survival curve and mortality compression were underway during the period 1921-2000, although occurring at a slower pace after 1960.

\section{A. Age distribution of deaths}

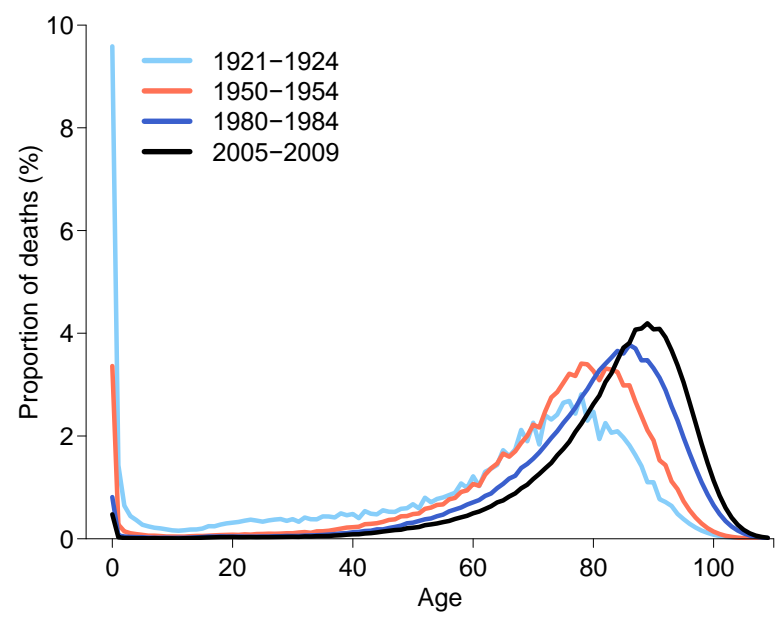

B. Survival curve

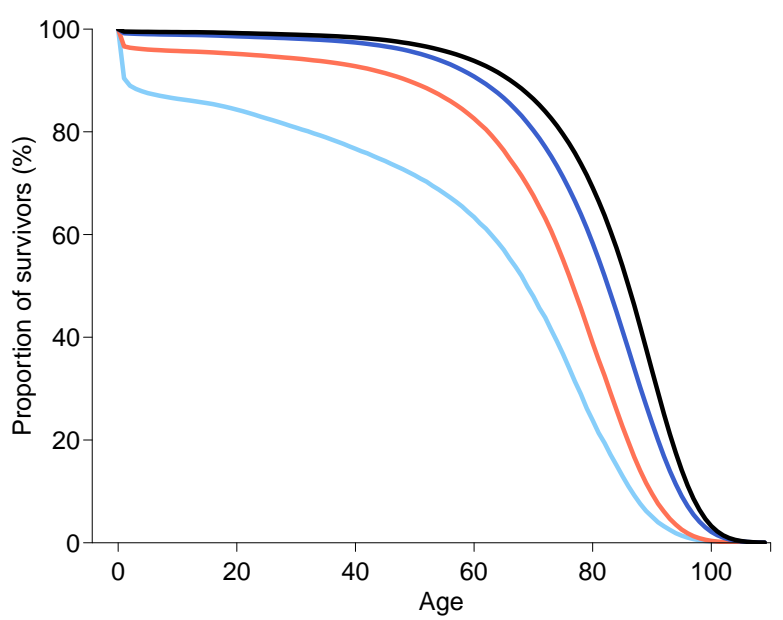

Figure 7. Changes in two life table functions: the age distribution of deaths and the survival curve for Canadian females, selected periods between 1921-24 and 2005-09.

Source: Canadian Human Mortality Database, 2014. 


\section{Life expectancy at birth and the modal age at death: Two central tendency measures portraying different stories}

While measures of variability or rectangularity are now widely used and acknowledged by population scientists, many disregarded them just a couple of decades ago. Measures of central tendency, in particular the life expectancy at birth $\left(\mathrm{e}_{0}\right)$, gathered the most interest at the time. As shown earlier in this paper, an effective summarization of statistical data on human longevity can indeed be obtained with the life expectancy at birth. In low-mortality countries, however, where deaths occur in a restricted age range, $\mathrm{e}_{0}$ may not be the proper indicator. In fact, increasing attention is lately being given to the adult modal age at death (i.e., the "typical" or most frequent age at death among adults).

Typically, the age distribution of deaths in human life tables is bimodal, with the first local mode at the left end (age 0) and the second local mode at an old age (denoted by M; Figure 8). The number of deaths recorded at the younger mode is greater than that at the older mode in high mortality regimes — as in Canada in 1921 — but deaths at the older mode are greater in low-mortality regimes — as in Canada in 2011. In the early 1920s, $\mathrm{e}_{0}$ for the female Canadian population was about 58 years and $\mathrm{M}$ was at 78 years, yielding a difference of 20 years because, unlike $\mathrm{e}_{0}$ - which is affected by mortality at all ages (young, middle, and old) - $\mathrm{M}$ is solely determined by old-age mortality (Horiuchi et al. 2013). Nowadays, the gap between the two measures may be comparatively small, about 7 years (90 minus 83 , according to 2011 data), but the mode is still more suitable as a longevity measure, given that lifespan extension is mainly due to the reduction in old-age mortality (e.g., Meslé and Vallin 2000; Wilmoth et al. 2000).

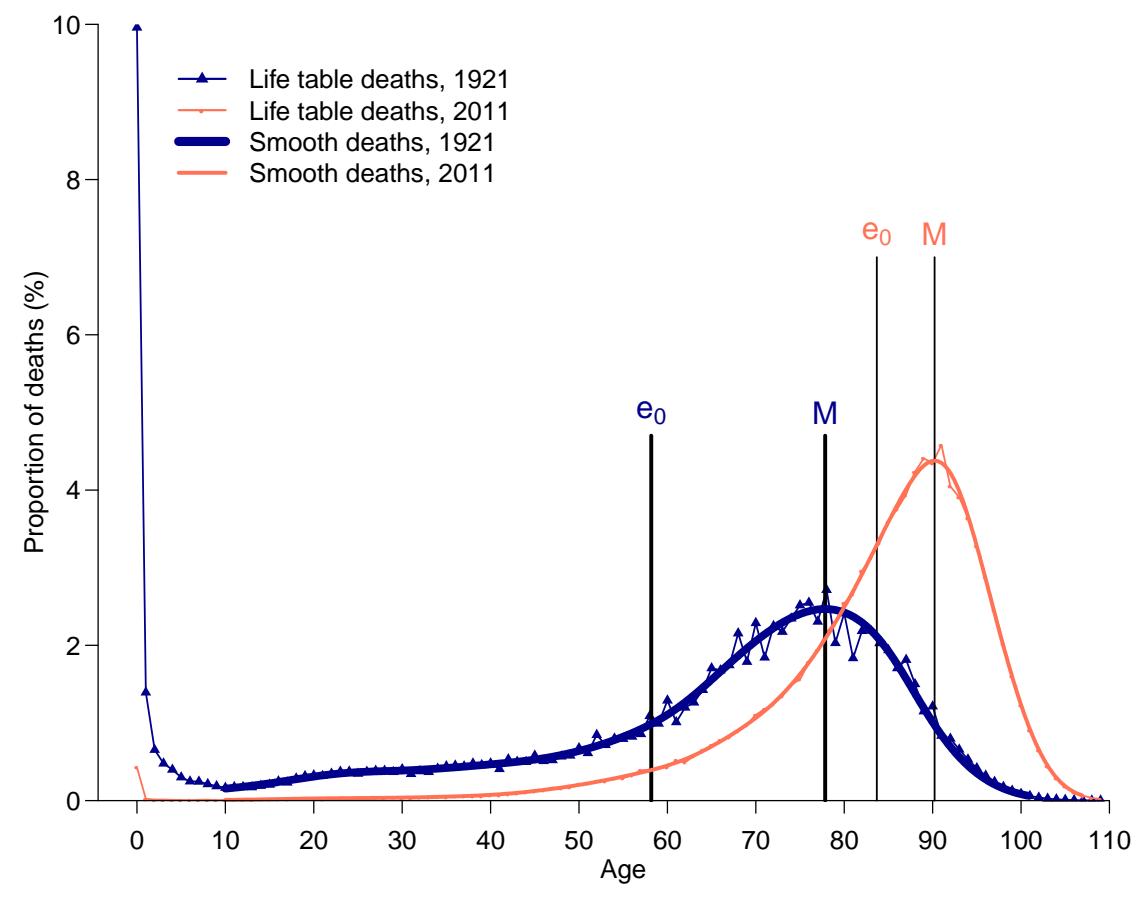

Figure 8. Modal age at death $(M)$ and life expectancy at birth $\left(e_{0}\right)$ for the age-at-death distribution for Canadian females in 1921 and 2011.

Source: Author's calculations based on the Canadian Human Mortality Database, 2014. Note: The smoothed age-at-death distribution curves for period life tables were directly derived from the P-spline-smoothed mortality curves based on penalised Poisson likelihood (one-dimensional smoothing over ages) (Ouellette and Bourbeau 2011). 
A. Modal age at death

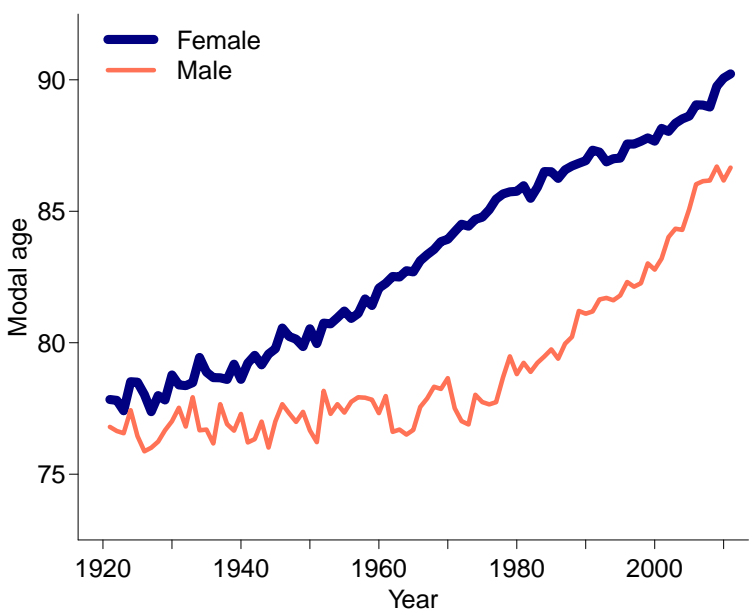

B. Standard deviation of ages at death above the mode

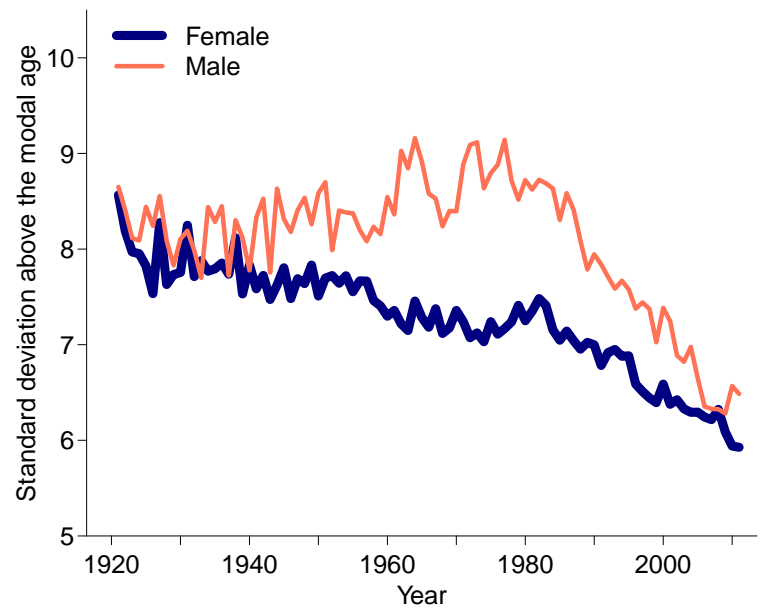

Figure 9. Adult modal age at death (M) and standard deviation of ages at death above the mode (SD(M+)) for females and males in Canada, 1921-2011.

Source: Author's calculations based on the Canadian Human Mortality Database, 2014.

Note: Annual values of $\mathrm{M}$ and $\mathrm{SD}(\mathrm{M}+)$ were computed from smoothed age-at-death distribution curves, which were directly derived from the P-spline-smoothed mortality curves based on penalised Poisson likelihood (one-dimensional smoothing over ages) (Ouellette and Bourbeau 2011).

Other widely used measures of old-age survival mentioned earlier in this paper are life expectancies at some selected old ages such as 65,75 , or $85\left(\mathrm{e}_{65}, \mathrm{e}_{75}\right.$, or $\left.\mathrm{e}_{85}\right)$. The life expectancy conditional on survival to the selected old age is obviously independent of mortality at young ages. However, as shown by Horiuchi et al. (2013), changes in these conditional life expectancies tend to underestimate the age shifts of old-age mortality. They also tend to be highly age-dependant; the underestimation intensifies as the starting age selected for the conditional life expectancy increases. M, on the other hand, captures mortality shifts more accurately, and is not subject to such dependency on the selected age range.

\section{Monitoring the compression of mortality at older ages}

As in most economically developed countries, the second half of the twentieth century was characterized by an unprecedented decline in old-age mortality in Canada. In this context of longevity extension, it has become more important to distinguish between old-age mortality compression and overall mortality compression (i.e., for the full age range). Up until the 1950s, death rates in childhood and young adult ages diminished markedly, and this was the major driving force of the overall compression of mortality. Afterwards, however, overall mortality compression was slower-see Martel and Bourbeau (2003) as well as Figure 7 for Canada—or halted in some populations (Wilmoth and Horiuchi 1999; Yashin et al. 2001).

In order to analyse changes in the age distribution of deaths at older ages, Kannisto (2001) proposed the following combination of summary measures: adult modal age at death $\mathrm{M}$ - to indicate the location of the death heap in old age - and standard deviation of individual life durations above $\mathrm{M}$, denoted by $\mathrm{SD}(\mathrm{M}+)$ - to size the variability of deaths among older people. A decline in $\mathrm{SD}(\mathrm{M}+)$ over time indicates that deaths above $\mathrm{M}$ are becoming increasingly compressed into a shorter age interval, hence the expression old-age mortality compression. 
Figure 9 shows estimated time-trends in $\mathrm{M}$ and $\mathrm{SD}(\mathrm{M}+)$ in Canada for each sex since 1921. Among females, $\mathbf{M}$ increased steadily and substantially throughout the period. In the early $1920 \mathrm{~s}, \mathrm{M}$ was about 78 years, and by 2011, it had increased by more than 10 years, reaching 90.2 years. Among males, the trajectory of $\mathrm{M}$ was almost flat until the late 1960s or even early 1970s. Values wiggled in the high 70s because mortality reductions at ages above M, essential for its increase (Canudas-Romo 2010), were limited during that time period. Afterwards however, M started to increase at a rapid pace, ending at 86.7 years in 2011, and the upward trend will likely continue in the future.

Regarding $\mathrm{SD}(\mathrm{M}+)$, Figure 9 reveals for both males and females that lower values were recorded at the end of the period studied than at the beginning. In other words, between 1921 and 2011 oldage mortality compression occurred. But it should be noted that the sex-specific trends in $\mathrm{SD}(\mathrm{M}+)$ did not decline steadily over time. For example, the 1960s and 1970s were periods of relative stagnation in $\mathrm{SD}(\mathrm{M}+)$ among Canadian females. These episodes demonstrate that a rise in $\mathrm{M}$ is not necessarily paralleled with a decrease in $\mathrm{SD}(\mathrm{M}+)$, as the general scenario of compression of mortality suggests. Other scenarios-such as the shifting mortality scenario, where the age distribution of death at older ages is assumed to move to the right without changing its shape (i.e., increasing trend in $\mathrm{M}$ accompanied by a flat trend in $\mathrm{SD}(\mathrm{M}+)$ ) — may provide better description in some cases. In fact, many low-mortality populations have clearly been involved in the shifting mortality for several years now (Bongaarts 2005; Cheung and Robine 2007; Canudas-Romo 2008; Cheung et al. 2008; Ouellette and Bourbeau 2011; Ouellette et al. 2012). In recent years, while some clues in support of the shifting mortality scenario were apparent among Canadian females (Ouellette and Bourbeau 2011), the latest data suggest that old-age mortality compression has continued for both sexes (Figure 9).

\section{New challenges}

\section{Causes of death}

Building on Omran's theory of epidemiologic transition (Omran 1971) and its revision by Olshansky and Ault (1986), Frenk and colleagues (1991) proposed the broader concept of health transition to account for both the extraordinary advances in health conditions of societies since the 18th century and the evolution of organized social response to these changing health conditions. The present section examines fundamental developments in cause-specific mortality over successive stages of health transition in Canada since 1950.

We computed age-standardized death rates by sex and broad groups of causes of death (see Table A-1 for a full listing) for single calendar years from 1950 to 2011 and for three selected periods (1950-54, 1979-83, and 2007-11), using the total Canadian population (both sexes) by five-year age groups in 1981 as the standard.

Cardiovascular diseases and malignant neoplasms have remained the leading causes of death in Canada from 1950 to 2011. Taken together, these two broad groups of diseases have accounted for no less than 59 per cent (and slightly above 70 per cent at most) of the all-cause age-standardized death rate since 1950 (Table 1). Up until very recently, cardiovascular disorders formed the largest group of the two. Indeed, in the early 1950s, the share of cardiovascular diseases in total mortality was more than 50 per cent for each sex, but the share dropped to about 25 per cent in 2011 because of the remarkable decline in cardiovascular mortality over time $(-75$ per cent for males and -80 per cent for females). The first two panels of Figures $10 \mathrm{~A}$ and $10 \mathrm{~B}$ provide a more detailed illustration, displaying the death rate trends since 1950 for the two main subcategories of cardiovascular disorders: heart diseases and cerebrovascular diseases. Despite differences in levels (the proportion of 
deaths attributable to heart diseases is considerably larger than that from cerebrovascular diseases in every calendar year, especially among males), the trends are similar. For females, the declining mortality trend was fairly steady for both groups of cardiovascular diseases until around 1990, and then commenced a period of slower decline. For males, the onset of the decline was delayed (around 1968 for heart diseases and slightly earlier for cerebrovascular diseases) and took place after a period of levelling-off in the mortality trend. It should be noted that males in many other high-income countries also experienced noticeable turning points in cardiovascular mortality trends in the late 1960s or early 1970s, at the beginning of the cardiovascular revolution (Ouellette et al. 2014).

From the malignant neoplasms cause-of-death category, we distinguished two groups: smokingrelated cancers and all other types of cancers, which currently account for respectively about one third and two thirds of the malignant neoplasms age-standardized death rate (Table 1). Figure 10A shows that mortality trends have been clearly diverging for these two groups among females: whereas

Table 1. Age-standardized death rate (per 10,000) and mortality proportion (\%) for broad cause-of-death categories by sex in Canada in 1950-54, 1979-83, and 2007-11 a

\begin{tabular}{|c|c|c|c|c|c|c|}
\hline \multirow{2}{*}{ Cause-of-death category } & \multicolumn{2}{|c|}{$1950-54$} & \multicolumn{2}{|c|}{$1979-83$} & \multicolumn{2}{|c|}{$2007-11$} \\
\hline & per 10,000 & $\%$ & per 10,000 & $\%$ & per 10,000 & $\%$ \\
\hline \multicolumn{7}{|l|}{ Males } \\
\hline Malignant neoplasms & 16.4 & 14.1 & 21.2 & 23.2 & 16.7 & 30.8 \\
\hline Smoking-related malignant neoplasms ${ }^{\mathrm{b}}$ & 3.2 & 2.8 & 8.0 & 8.8 & 5.8 & 10.7 \\
\hline Other malignant neoplasms & 13.2 & 11.3 & 13.2 & 14.4 & 10.9 & 20.1 \\
\hline Cardiovascular diseases & 60.5 & 52.1 & 42.6 & 46.7 & 15.1 & 27.9 \\
\hline Heart diseases & 44.9 & 38.6 & 32.9 & 36.0 & 11.7 & 21.7 \\
\hline Cerebrovascular diseases & 12.0 & 10.4 & 6.6 & 7.3 & 2.5 & 4.6 \\
\hline Other cardiovascular diseases & 3.6 & 3.1 & 3.2 & 3.5 & 0.9 & 1.6 \\
\hline Infectious and parasitic diseases & 3.4 & 2.9 & 0.4 & 0.5 & 1.1 & 2.1 \\
\hline Respiratory diseases & 6.7 & 5.7 & 7.3 & 8.1 & 4.7 & 8.7 \\
\hline Other diseases & 18.7 & 16.1 & 10.5 & 11.6 & 11.2 & 20.7 \\
\hline Deaths from external causes & 10.5 & 9.1 & 9.1 & 10.0 & 5.3 & 9.9 \\
\hline All causes & 116.1 & 100.0 & 91.3 & 100.0 & 54.1 & 100.0 \\
\hline \multicolumn{7}{|l|}{ Females } \\
\hline Malignant neoplasms & 14.5 & 16.8 & 13.3 & 25.6 & 12.0 & 33.5 \\
\hline Smoking-related malignant neoplasms ${ }^{\mathrm{b}}$ & 0.8 & 0.9 & 2.0 & 3.9 & 3.5 & 9.6 \\
\hline Other malignant neoplasms & 13.8 & 15.9 & 11.3 & 21.7 & 8.6 & 23.9 \\
\hline Cardiovascular diseases & 45.8 & 52.9 & 24.6 & 47.3 & 9.1 & 25.3 \\
\hline Heart diseases & 30.4 & 35.1 & 17.2 & 33.1 & 6.5 & 18.0 \\
\hline Cerebrovascular diseases & 12.7 & 14.7 & 5.5 & 10.6 & 2.1 & 6.0 \\
\hline Other cardiovascular diseases & 2.7 & 3.2 & 1.8 & 3.6 & 0.5 & 1.4 \\
\hline Infectious and parasitic diseases & 2.3 & 2.7 & 0.3 & 0.5 & 0.8 & 2.2 \\
\hline Respiratory diseases & 4.9 & 5.6 & 3.0 & 5.7 & 2.9 & 8.2 \\
\hline Other diseases & 15.1 & 17.4 & 7.4 & 14.3 & 8.8 & 24.5 \\
\hline Deaths from external causes & 3.9 & 4.5 & 3.4 & 6.6 & 2.2 & 6.2 \\
\hline All causes & 86.5 & 100.0 & 51.9 & 100.0 & 35.9 & 100.0 \\
\hline
\end{tabular}

Source: Author's calculations based on data from Statistics Canada (1950-99: special tabulations; 2000-11: CANSIM database, Table 102-0521) and from the Canadian Human Mortality Database, 2014.

Note: Deaths from ill-defined causes were distributed proportionally across the broad groups of well-defined causes. They represent less than $1.5 \%$ of total deaths (between $0.6 \%$ and $2.8 \%$ for each sex and year over the 1950-2011 period).

${ }^{a}$ The standard population corresponds to the total Canadian population (both sexes) in 1981. The content of each group of causes of death is described in Table A-1.

${ }^{\mathrm{b}}$ Includes all deaths from malignant neoplasms of lip, oral cavity, pharynx, oesophagus, larynx, trachea, bronchus, and lung as the underlying cause. 

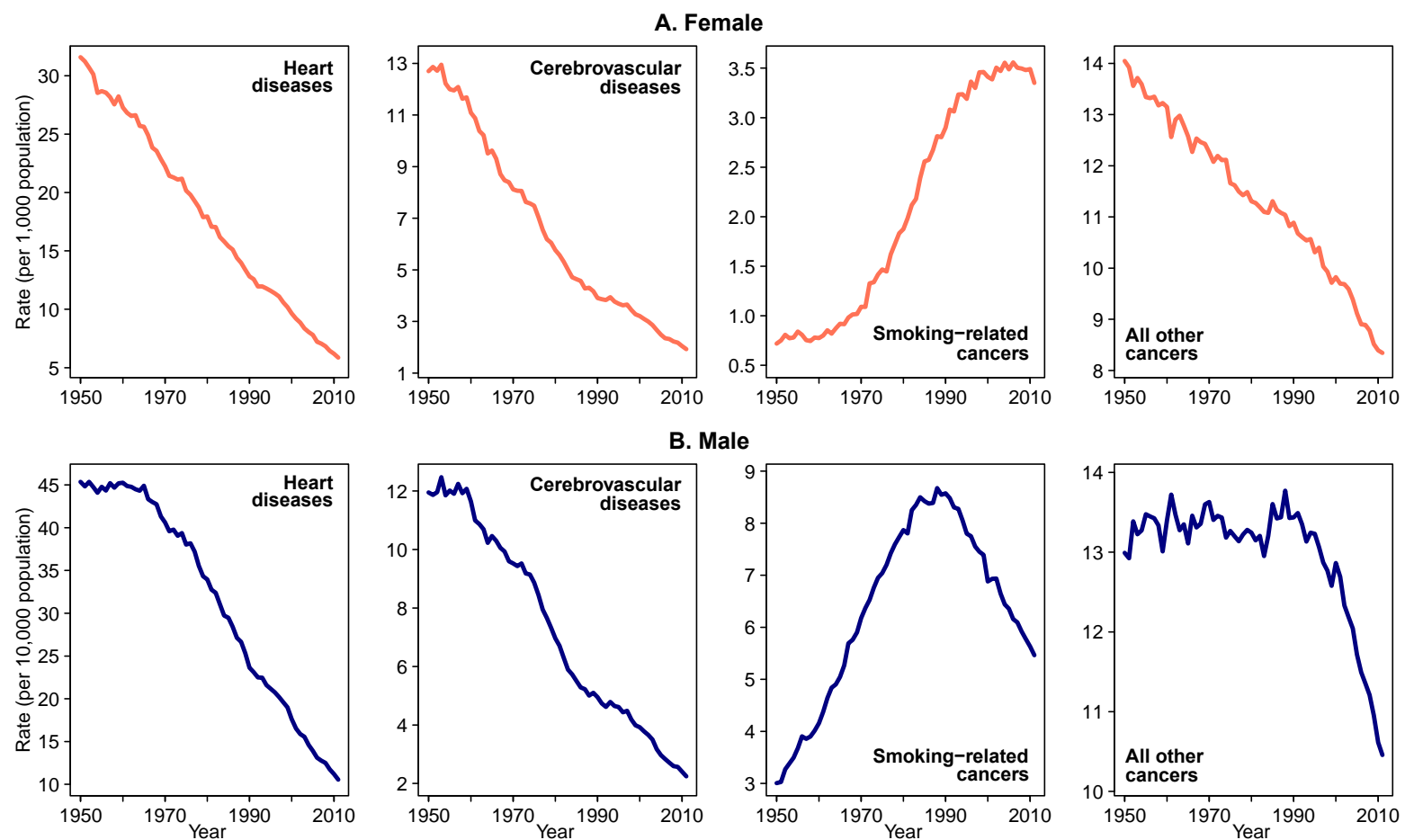

Figure 10. Age-standardized death rates for selected causes of death for females and males in Canada, 1950-2011.

Source: See Table 1.

Notes: The standard population corresponds to the total Canadian population (both sexes) in 1981. The smoking-related cancer death rate includes all deaths from malignant neoplasms of lip, oral cavity, pharynx, oesophagus, larynx, trachea, bronchus, and lung as the underlying cause.

death rates from smoking-related cancers increased throughout most of the period studied (death rates recently reached a plateau at a level 5 times higher than 50 years earlier), mortality from other forms of cancers has declined continuously since 1950. Among males, trends for the two groups also differ, but less strikingly: whereas mortality from smoking-related cancers started to decline steeply at the end of the 1980s after a long period of sustained increase, death rates for all other cancers began to fall around 1990, following an extended period of levelling-off. The substantial differences by sex for cancers closely related to smoking in Canada (and in many other high-income countries as well) reflect the very distinct trends in tobacco consumption between males and females over the past 60 years. The recent stagnating mortality trend among females could mark the start of a new era.

The "other diseases" cause-of-death category is the third-largest group of causes in Canada since 1950. It currently accounts for as much as 21 per cent and 25 per cent of the male and female all-cause age-standardized death rates, respectively (Table 1). This disease category combines a large spectrum of conditions, each with its own set of etiological factors, which makes the overall patterns rather difficult to interpret. However, the very rapid decline in death rates recorded between 1950-54 and 1979-83 ( -44 per cent for males and -51 per cent for females) was in large part driven by reductions in infant mortality due to congenital malformations or birth trauma.

Since the 1970s, mortality from external causes of death has declined considerably, especially among Canadian males, where the death rate is now about half of what it used to be (Table 1). Deaths from external causes mostly involve male teenagers and young adults aged 15-44 in Canada, and improvements in mortality due to vehicle and traffic injuries greatly contributed to the progress observed in the last $30-40$ years. 
After a sustained increase in male and female death rates for respiratory diseases during the 1980s and 1990s, due mostly to a rise in deaths from chronic obstructive pulmonary disease attributable to tobacco consumption, mortality declined continuously afterwards. However, the share of respiratory diseases in total mortality has increased over time (Table 1) as these diseases are more common among the elderly-especially the very old, who have become one of the fastest growing segments of the Canadian population (Statistics Canada 2012a). With this aging phenomenon, it is essential to fill the current gaps in knowledge about the health of the elderly population. A better understanding of morbidity and mortality due to respiratory disease is a particularly important part of this effort.

\section{Emergence of centenarians}

The unanticipated decline in mortality above age 80, and especially the magnitude of this decline after 1970, was a pleasant surprise. Works by Kannisto (1994) and by Thatcher and colleagues (1998) in the 1990s were the first to report these as-yet-unknown mortality improvements at older ages. Exploiting data for a large set of high-income countries, these authors showed that age-standardized death rates for ages 80-99 fell significantly over time, although the rate of mortality decline varied by country.

Great improvements in survival at older ages have also been recorded in Canada (Bourbeau and Lebel 2000) and caused what was described as an "explosion" of the number of centenarians. The size of the total centenarian population (both sexes) grew 25-fold over six decades, from slightly above 200 in 1951 to nearly 5,300 in 2011 (Figure 11). Between 2006 and 2011, this was one of the most rapidly growing age groups of all, with an increase of more than 20 per cent (Statistics Canada

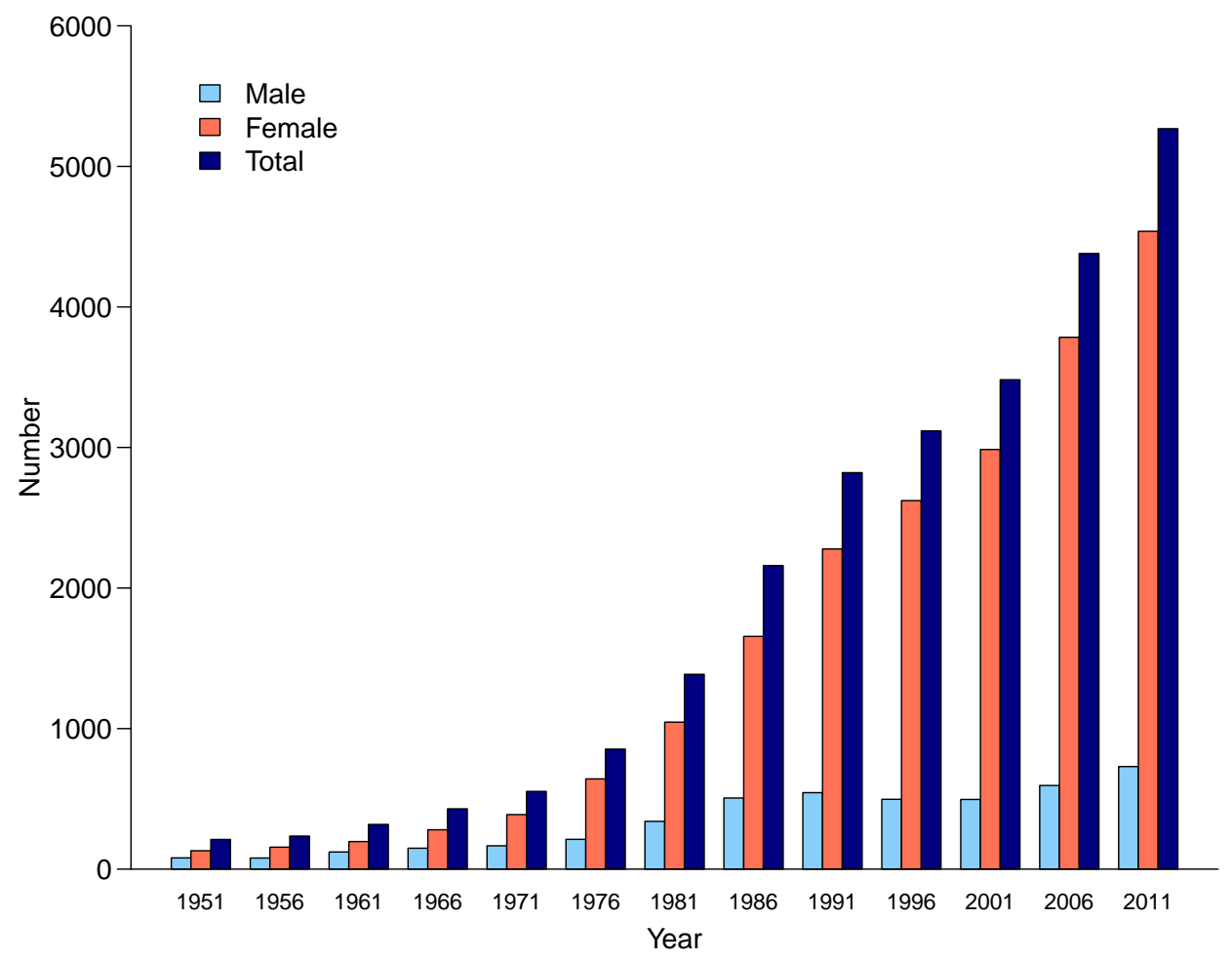

Figure 11. Number of centenarians for females and males in Canada, 1951-2011. Sources: 1951-96: Canadian Human Mortality Database, 2014; 2001-11: Statistics Canada, CANSIM database (Table 051-0001).

Note: Estimated numbers of individuals aged 100 and above at $1^{\text {st }}$ July in each year. 
2012a). Moreover, the total number of centenarians in Canada could more than triple by 2031 and exceed 17,000 (Statistics Canada 2012b).

Given that females experience lower risks of death at every age compared to males, they are much more likely to reach the age of 100 than their male counterparts. In 2011, 85 per cent of Canadian centenarians were females. It is noteworthy that at the time of writing, the fourth-oldest verified person ever is Canadian: Marie-Louise Meilleur was born in 1880 and died in 1998 at age 117.6 (Desjardins 1999). She became the oldest verified living person in 1997 after Jeanne Calment's death ${ }^{6}$ and held the title for close to nine months afterwards.

The number of centenarians is rising very rapidly in several other high-income countries, too. In Japan for instance, the population of centenarians was estimated at nearly 55,000 for 2013, yielding the world's highest rate, at more than 37.0 per 100,000 inhabitants. Canada counted about 17.4 centenarians per 100,000 in 2011, a share that is just below the average value for all G8 countries (Statistics Canada 2012b).

\section{Healthy life expectancy}

Declines in old-age mortality over time and the unprecedented numbers of people surviving to old and very old ages raise important questions about the quality of life. To determine whether extra years of life gained through increased longevity are mostly lived in good health (compression of morbidity scenario) or whether a greater share of these years are lived with disability, dependence, and/ or handicap (expansion of morbidity scenario), one needs to assess the health status of the population. This implies developing new concepts-including that of disability, loss of autonomy, and social participation - and proposing indicators to monitor the health status of individuals and populations.

In Canada, interest in measuring health status goes back to 1950-51, when the first nationwide survey on health was conducted (Statistics Canada 1987). But the first estimated values of healthy life expectancy emerged only in the 1970s (Statistics Canada 1981, with linked data from the 1978-79 Canada Health Survey to the 1976 Canadian census), based on the Sullivan method (1971). Most cross-sectional surveys provide point estimates of the magnitude of the incapacity, disability, or poor health outcomes of individuals. These estimates then allow to disentangle the total number of years lived from those lived in good and poor health, and finally to compute values of life expectancy (LE) — at birth or at any other age-according to the selected health criteria (disability-free LE, handicap-free LE, health-adjusted LE, etc.).

Changes in healthy life expectancies could thus be monitored over time to determine whether a given population experiences compression or expansion of morbidity. The task is, however, quite challenging, because the data are often not comparable from one survey to the next-owing to the varying definition of health concepts, notably — or because periodic surveys are lacking. In fact, in Canada, the data available do not allow the study of long-term trends (Bourbeau et al. 2011). Studies over short-time periods prior to the mid-1990s reveal that gains in life expectancy have been roughly equally distributed between years lived with and without disability or dependence (Wilkins and Adams 1992; Roberge et al. 1999; Carrière and Légaré 2000; Martel and Bélanger 2006).

A recent Canadian study by Mandich and Margolis (2014) has enriched our knowledge by examining changes in disability-free life expectancy by sex between 1994 and 2007. Using data from two nationally representative surveys - the 1994-95 National Population Health Survey and the 2007-08 Canadian Community Health Survey - they define disability in two ways, reporting in terms of needing help with

6. Jeanne Calment was born in France in 1875 and died in 1997 at age 122.4 (Robine and Allard 1999). She is currently known as the oldest verified person who has ever lived. 
at least one of the five everyday tasks ${ }^{7}$ and needing help with at least two of these tasks. The results of the study differ by sex. For males, the findings do not clearly support either the compression or expansion of morbidity, because there were increases in both disability-free life expectancy and disabled years between 1994 and 2007. By contrast, female gains in life expectancy over the period consisted mostly of disabled instead of healthy years, thus supporting the expansion of morbidity scenario. For instance, Canadian females aged 70 can expect to live 17.2 more years in 2007 compared to 15.9 in 1994, but out of the 1.3 years of life gained, 1.2 years (92 per cent) are spent with disability. In sum, these findings indicate that the number of Canadians - females in particular — who require assistance with their daily activities is increasing. Public health policy adjustments to this reality are imperative.

\section{The challenge of combating obesity}

The growing presence of risk factors such as obesity, unhealthy diet, and physical inactivity among human populations supports arguments by some scholars - mainly social biologists-foreseeing a levelling-off or even a decline in life expectancy at birth and at older ages in the 21st century (Olshansky et al. 2005). The findings concern the United States, in particular, where obesity rates recorded in the early 2000s were especially high: " 28 percent of men, 34 percent of women, and nearly 50 percent of non-Hispanic black women are currently obese [body mass index (BMI) between 30 and 35 $\mathrm{kg} / \mathrm{m}^{2}$ ]" (Olshansky et al. 2005: 1139). However, a recent study by Preston and colleagues (2014) sheds a different light on the topic by analyzing the effects of changes in obesity and smoking on future trends in life expectancy at age $40\left(\mathrm{e}_{40}\right)$ in the United States. Because gains in $\mathrm{e}_{40}$ from reduced smoking will exceed losses from increased obesity, $\mathrm{e}_{40}$ should continue to increase over the next 30 years in the United States, with projected net gains of 0.83 years for males but only 0.09 years for females. ${ }^{8}$

Nonetheless, obesity remains a matter of concern in Canada, both in terms of the burden of the disease and its financial consequences: obesity increases the risk of developing chronic diseases (e.g., cardiovascular diseases, diabetes, some types of cancers), and it has been estimated that in 2008 obesity cost the Canadian economy roughly $\$ 4.6$ billion, up $\$ 735$ million since 2000 (PHAC-CIHI 2011).

The overall national prevalence of self-reported obesity more than doubled between 1985 and 1998 in Canada, rising from 6 per cent to 15 per cent (Katzmarzyk 2002). According to the latest estimations, obesity rates corrected for self-report bias reached nearly 23 per cent in 2003 and 25 per cent in 2011, thus confirming a continued increase in the prevalence of obesity across the country over the past decade (Gotay et. al 2013). There is possibly a flattening since 2009 but it remains to be seen whether this trend will endure. In general, estimated obesity rates vary little by sex in Canada, but regional differences exist, with Atlantic provinces and the territories (except Yukon) having the highest values (current rates exceed 30 per cent) and British Columbia and Quebec the lowest ones (current rates below 25 per cent).

As to what are the direct effects of obesity on mortality, they are not well understood because it remains difficult to disentangle obesity's own effect on mortality from that of other risk factors, comorbidities, and confounding variables. A Canadian study has estimated that 9.3 per cent of all deaths recorded at ages 20-64 in 2000 could be attributed to overweight and obesity (Katzmarzyk and Ardern 2004). There is no doubt that obesity will continue to be a serious public health challenge in Canada, by increasing the number of years spent in poor health rather than reducing the total years lived.

7. The comparable tasks in both surveys have to do with preparing meals, personal care, moving about inside the house, doing housework, and leaving the house to attend somewhere or to pick up items.

8. These results differ from those of Stewart et al. (2009), who forecast negative net gains for both sexes combined over the period 2005-20. 
Bourbeau and Ouellette: Trends, patterns, and differentials in Canadian mortality (1921-2011)

\section{Geographic disparities in mortality}

In terms of regional mortality conditions, all Canadian provinces have recorded substantial mortality progress over the period 1921-2011 (Figure 12). Previous studies have shown that these mortality improvements tended to reduce any disparities that prevailed among them (Field 1980; Wilkins 1980; Adams 1990; Nault 1997). Such a finding is in line with the proposal that Canadian regions are becoming increasingly homogeneous in terms of their economic and socio-demographic characteristics over time (Matthews and Davis 1986; Goyder 1993). In spite of that, regional mortality differentials persist in Canada. For instance, long-standing geographical disparities continue to exist in favour of provinces in the Western part of the country compared to those in the East. More recent findings even suggest that since the late 1980s, the traditional east-west gradient might have clarified further into a well defined east-central-prairies-west gradient (Manuel and Hockin 2000; Prud'homme 2007), thereby confirming that regional mortality disparities are still worth documenting in Canada.

Studies reporting the prevalence of several major well-established risk behaviours and health conditions for cardiovascular disease by province help elucidate these provincial mortality disparities (Health Canada 1995; PHAC 2009). The life expectancy advantage of the westernmost Canadian provincesBritish Columbia in particular-with respect to the other provinces is clearly reflected in their lower prevalence of smoking, physical inactivity, high blood pressure, and obesity. Nativity composition of the population in each province also proves helpful for understanding regional mortality differentials in Canada. Since immigrants account for a much larger share of the total population in western provinces, especially British Columbia, rather than Atlantic provinces, western provinces are likely to be advantaged in terms of overall mortality conditions (bealtby immigrant effect). Moreover, immigrants established in western provinces may even experience lower mortality than those living in Atlantic provinces, because a greater part of them originate from non-European countries, namely Asia (Chen et al. 1996; Bourbeau 2002a).

A recent study focusing on mortality at adult and older ages reveals another aspect of geographical disparities in Canada (Ouellette et al. 2012). Using the adult modal age at death (M) and standard deviation of individual life durations above $\mathrm{M}(\mathrm{SD}(\mathrm{M}+))$ to summarize the age distribution of deaths (see the section "Monitoring the compression of mortality at older ages"), the authors show that provincial disparities in old-age mortality have hardly decreased between 1930 and 2007, with western and central provinces currently displaying a clear survival advantage. Furthermore, some evidence of the shifting mortality regime was observed among females for a few western and central provinces, whereas all other populations were still undergoing an old-age mortality compression regime.

The Northwest Territories, Nunavut, and Yukon were excluded from Figure 12 mainly because of their relatively small population size, leading to substantial fluctuations, and also in that their data series are relatively shorter. Moreover, the territories are not directly comparable to other Canadian regions, due to their distinctive ethnic composition, consisting mostly of Aboriginal populations (First Nations, Métis, and Inuit). Life expectancy at birth values for the territories are relatively low, especially for males and females in Nunavut, who currently live on average 10 years less than all Canadians (Statistics Canada 2013b). Corresponding differences are smaller for the Northwest Territories and Yukon, about 3-4 years, but worrying nonetheless. Higher levels of infant, juvenile, and young adult mortality play major roles in explaining these disparities.

\section{Socioeconomic inequalities in health}

Socioeconomic inequalities in health persist. According to a deprivation index based on information collected at the micro-geographic level (Pampalon et al. 2009a), the life expectancy at age 25 of Canadian males living in advantaged neighborhoods in 1991-2001 was 4.4 years greater than that of 


\section{A. Female}

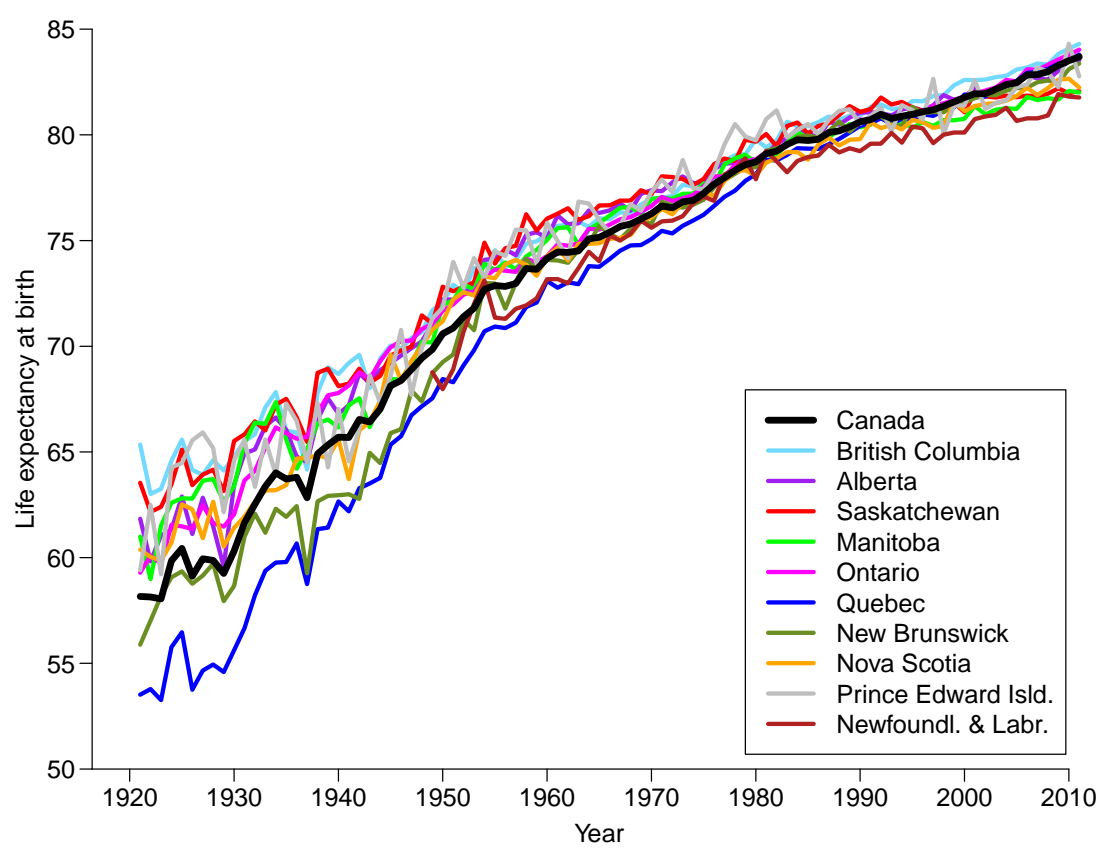

B. Male

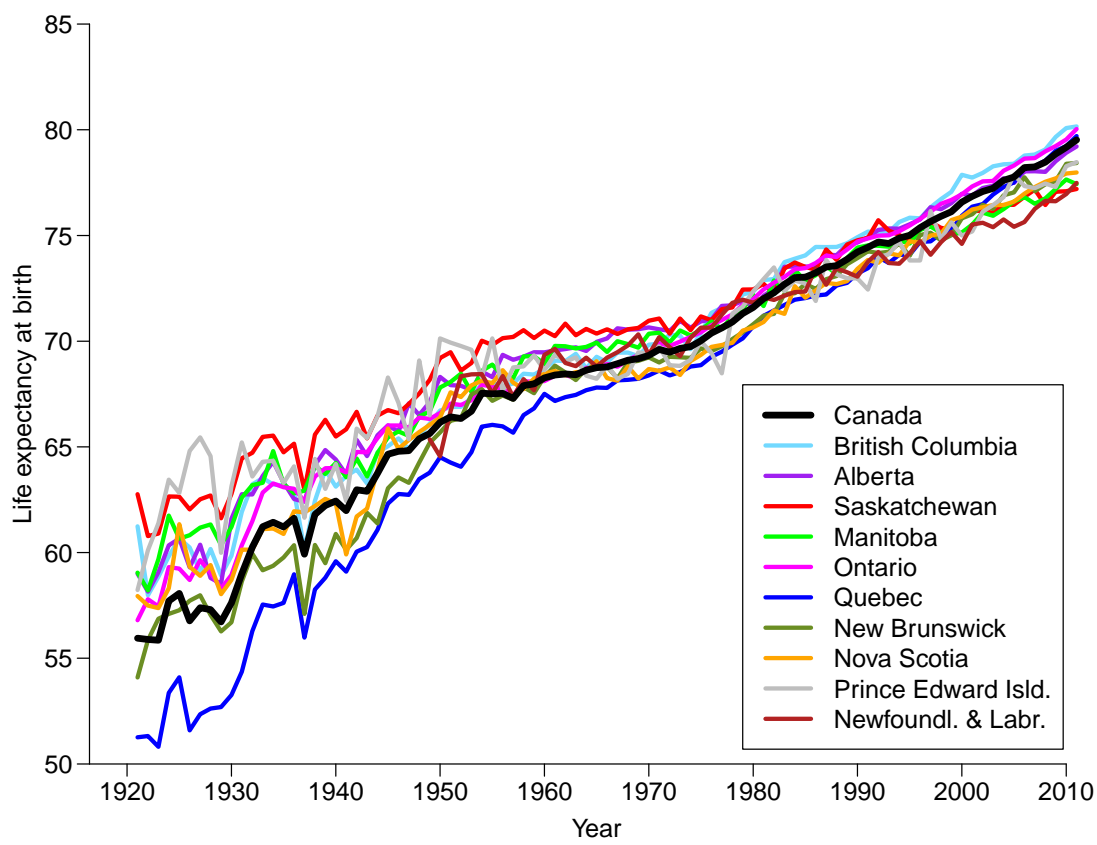

Figure 12. Life expectancy at birth for females and males, Canadian provinces, 1921-2011.

Source: Canadian Human Mortality Database, 2014.

males living in disadvantaged neighborhoods (Pampalon et al. 2009b); for women, the gap was 2.9 years. Moreover, social and material inequalities in health have likely worsened in Canada: the ratio of age-standardized mortality rates between the extreme quintiles of material and social disadvantage rose from 2.0 in 1989-93 to 2.6 in 1999-2003, for males and females aged under 75 (Pampalon et al. 2009c). 
As opposed to several European countries, the United States, and New Zealand, Canada has long lacked nationally representative population-based cohort studies allowing researchers to fully examine the effect of socioeconomic status (SES) on mortality. This gap was filled partly in recent years by the Canadian census mortality follow-up study, an initiative of Statistics Canada to link mortality data from the Canadian Vital Statistics Death Database for the period 1991-2006 to the 1991 Canadian census data (Wilkins et al. 2008).

With these linked-data, it is possible to analyze all-cause mortality differences according to several socioeconomic factors (Wilkins et al. 2008; Mustard et al. 2013), in particular, place of birth (Omariba et al. 2014; Omariba 2015) and ethnic origin or Aboriginal identity (Tjepkema et al. 2009, 2010, 2012a), as well as cause-specific mortality differences by occupation and skill level (Mustard et al. 2010; Tjepkema et al. 2013b), by educational attainment (Tjepkema et al. 2012b), and by income level (Tjepkema et al. 2013a). In most cases, the studies find a gradient in mortality favouring persons of higher SES (with skilled jobs, higher levels of education, higher incomes, etc.), with the greatest differences recorded for causes of death that are closely related to tobacco and alcohol consumption. The gradient is also usually steeper at the lower rather than the higher end of the socioeconomic hierarchy, meaning that in the perspective of reduction or even elimination of health disparities, future declines in mortality would then be more pronounced for disadvantaged rather than advantaged groups.

\section{Conclusion}

\section{Mortality projections for Canada and comparison with other low-mortality countries}

To conclude, we shall look into the future and examine the various mortality projection scenarios that are currently available. In Canada, official statistics agencies often prepare projections as part of the development of population perspectives. At the federal level, Statistics Canada carries out periodic projections, with the latest results dating from 2014 (Statistics Canada 2014b). The Office of the Chief Actuary of Canada also conducts mortality projections for the Actuarial Report on the Canada Pension Plan (Office of the Chief Actuary 2012).

According to Statistics Canada, life expectancy at birth $\left(\mathrm{e}_{0}\right)$ could reach 87.6 years among males and 89.2 years among females in 2063 under a so-called medium-growth or central scenario. There are of course uncertainties about the future, which are reflected by a less favourable (low-growth) scenario, where $\mathrm{e}_{0}$ would reach 86 and 87.3 years, respectively, for males and females; a more optimistic scenario (bigh-growth), on the other hand, suggests that $\mathrm{e}_{0}$ would increase to 89.9 and 91.9 years for each sex, respectively, in 2063 (Statistics Canada, 2014b). The Office of the Chief Actuary's 2012 mortality projections are, on average, more conservative: male $\mathrm{e}_{0}$ would attain 85.7 years, and female $\mathrm{e}_{0} 88.6$ years, in 2075 .

Table 2 allows comparisons between projections for Canada and for a set of 9 selected countries, made by their respective statistical offices. It should be noted, however, that these comparisons must be made carefully, keeping in mind that the expectations of life projected are likely produced using different assumptions about the pace and extent of mortality change in each of the countries over the projection period. The projection methodologies may also differ by country. From a general point of view, Table 2 shows that all offices foresee a continued growth of $\mathrm{e}_{0}$ over the next 50 years. According to central scenarios presented in the table, Canada would remain among the countries with the lowest levels of mortality-in particular for males, where Canadian projections of $\mathrm{e}_{0}$ rank them 
first, just above those for the United Kingdom. Among females, the French are projected to overtake the Japanese in the next five decades, with a value of $\mathrm{e}_{0}$ exceeding 91 years in 2060. In the United Kingdom, the Office for National Statistics forecasts that with a 90-year life expectancy at birth in 2062, about 60 per cent of UK females would survive to age 90 and 20 per cent to age 100, making 95 years the modal age at death (ONS 2013). These figures certainly render even more relevant the longstanding debate about whether humans possess an immutable lifespan limit.

Table 2. Period life expectancy at birth (in years) in 2012 and projected ${ }^{\mathrm{a}}$ to around 2060 for Canada and other selected countries

\begin{tabular}{lrrrr}
\hline \multirow{2}{*}{ Country } & \multicolumn{2}{c}{$2010 / 2012^{\mathrm{b}}$} & \multicolumn{2}{c}{$2060 / 2061 / 2062^{\mathrm{c}}$} \\
\cline { 2 - 5 } & Males & Females & Males & Females \\
\hline Canada & 79.6 & 83.8 & 87.6 & 89.2 \\
\hline Australia & 79.7 & 84.2 & 85.2 & 88.3 \\
France & 78.5 & 84.8 & 86.0 & 91.1 \\
Japan & 79.9 & 86.4 & 84.2 & 90.9 \\
Netherlands & 79.1 & 82.8 & 84.5 & 87.4 \\
Norway & 79.4 & 83.4 & 86.2 & 89.3 \\
Sweden & 79.5 & 83.4 & 84.9 & 87.0 \\
Switzerland & 80.5 & 84.7 & 86.1 & 90.2 \\
United Kingdom & 79.0 & 82.7 & 87.3 & 90.3 \\
United States & 75.7 & 80.8 & 82.8 & 86.8 \\
\hline Sources: For Canada, Statistics Canada (2014b); for France, INSEE (2010); for \\
all other countries, Office for National Statistics (2013). \\
aCentral scenarios. \\
b2010 for the United States and 2012 for all other countries. \\
c2060 for the Netherlands, the United States, and France, 2061 for Australia, and \\
2062 for all other countries.
\end{tabular}

Despite the greater presence of factors such as obesity, climate change, and air pollution that may adversely affect future human longevity increases (Finch et al. 2013), projections are heading in the same direction: over the next 50-60 years, $\mathrm{e}_{0}$ will continue to rise not only in Canada but also in most low-mortality countries. This entails a wide range of challenges for societies, especially in regards to providing care to increasingly larger numbers of old and very old people, as well as persistent socioeconomic inequalities.

\section{References}

Adams, O. 1990. Life expectancy in Canada: An overview. Health Reports 2(4):361-76.

Andreev, K. 2000. Sex differentials in survival in the Canadian population, 1921-1997: A descriptive analysis with focus on age-specific structure. Demographic Research 3(12):19p.

Bah, S.M., and F. Rajulton. 1991. Has Canadian mortality entered the fourth stage of the epidemiologic transition. Canadian Studies in Population 18(2):18-41.

Barbieri, M., and N. Ouellette. 2012. The demography of Canada and the United States from the 1980s to the 2000s: A summary of changes and a statistical assessment. Population-E 67(2):177-280.

Baxter, D., and A. Ramlo. 1998. What Can You Expect: Life Expectancy in Canada, 1921 to 2021. Vancouver: Urban Futures Institute. 
Bourbeau and Ouellette: Trends, patterns, and differentials in Canadian mortality (1921-2011)

Beaujot, R.P., and D. Kerr. 2003. Population Change in Canada. Toronto: Oxford University Press.

Bergeron, M-P. 2012. Changements épidémiologiques au Canada : un regard sur les causes de décès des personnes âgées de 65 ans et plus, 1979-2007. Master’s thesis, Université de Montréal, Département de démographie.

Bongaarts, J. 2005. Long range trends in adult mortality: Models and projection methods. Demography 42(1):23-49.

Bourbeau, R. 2002a. L'effet de la "sélection d'immigrants en bonne santé" sur la mortalité canadienne aux grands âges. Cahiers québécois de démographie 31(2):249-74.

- 2002b. Canadian mortality in perspective: A comparison with the United States and other developed countries. Canadian Studies in Population 29(2):313-369.

Bourbeau, R., and J. Légaré. 1982. Évolution de la mortalité an Canada et an Québec 1831-1931: Essai de mesure par génération. Démographie canadienne 6. Montréal: Presses de l’Université de Montréal.

Bourbeau, R., and A. Lebel. 2000. Mortality statistics for the oldest-old: An evaluation of Canadian data. Demographic Research 2:36p.

Bourbeau, R., J. Légaré, and N. Ouellette. 2011. Revue de la littérature sur l'évolution future de l'espérance de vie et de l'espérance de vie en santé. Social and Economic Dimensions of an Aging Population 289:101p.

Camarda, C.G. 2012. MortalitySmooth: An R package for smoothing Poisson counts with P-splines. Journal of Statistical Software 50(1):1-24.

Canadian Human Mortality Database. 2014. Université de Montréal (Canada), University of California, Berkley (USA), and Max Planck Institute for Demographic Research (Germany). Accessed via http://www. bdlc.umontreal.ca (data downloaded on [25/07/2014]).

Canudas-Romo, V. 2008. The modal age at death and the shifting mortality hypothesis. Demographic Research 19:1179-1204.

—. 2010. Time trends and record values for longevity. Demography 47(2):299-312.

Carrière, Y., and J. Légaré 2000. Unmet need for assistance with ADLs and IADLs: A measure of healthy life expectancy. Social Indicators Research 51(1):107-23.

Caselli, G., J.W. Vaupel, and A.I. Yashin. 1985. Mortality in Italy: Contours of a century of evolution. Genus 41(1-2):39-55.

Caselli, G., F. Meslé, and J. Vallin. 2002. Epidemiologic transition theory exceptions. Genus 58(1):9-51.

Charbonneau, H., Y. Lavoie, and J. Légaré. 1972. Étude des caractéristiques nominatives dans l'état civil et les recensements canadiens du XVIIe siècle : prélude à l'utilisation des ordinateurs pour le jumelage des données. Annales de démographie historique 72:269-95.

Chen, J., R. Wilkins, and E. Ng. 1996. Health expectancy by immigrant status, 1986 and 1991. Health Reports 8(3):29-38.

Cheung, S.L.K., and J-M. Robine. 2007. Increase in common longevity and the compression of mortality: The case of Japan. Population Studies 61(1):85-97.

Cheung, S.L.K., J-M. Robine, E.J-C. Tu, and G. Caselli. 2005. Three dimensions of the survival curve: Horizontalization, verticalization, and longevity extension. Demography 42(2):243-58. 
Cheung, S.L.K., J-M. Robine, and G. Caselli. 2008. The use of cohort and period data to explore changes in adult longevity in low mortality countries. Genus LXIV(1-2):101-29.

Decady, Y., and L. Greenberg. 2014. Ninety Years of Changes in Life Expectancy: Health at a Glance. Catalogue no. 82-624-X. Ottawa: Statistics Canada.

Desjardins, B. 1999. Did Marie Louise Meilleur become the oldest person in the world? In Validation of Exceptional Longevity, edited by B. Jeune and J.W. Vaupel. Odense: Odense University Press, pp. 189-94.

Eilers, P.H.C., and B.D. Marx. 1996. Flexible smoothing with B-splines and penalties (with discussion). Statistical Science 11(2):89-121.

Field, N.C. 1980. Temporal trends and spatial patterns of mortality in Canada, in Canadian Studies in Medical Geography, edited by F.A. Barrett. Toronto: Department of Geography, Atkinson College, York University, pp. 32-58.

Finch, C.E., H. Beltrán-Sánchez, and E.M. Crimmins. 2013. Uneven futures of human lifespans: Reckonings from Gompertz mortality rates, climate change, and air pollution. Gerontology 60(2):18388 .

Frenk, J., J.L. Bobadilla, C. Stern, T. Frejka, and R. Lozano. 1991. Elements for a theory of the health transition. Health Transition Review 1(1):21-38.

Gotay, C.C., P.T. Katzmarzyk, I. Janssen, M.Y. Dawson, K. Aminoltejari, and N.L. Bartley. 2013. Updating the Canadian obesity maps: An epidemic in progress. Canadian Journal of Public Health 104(1):e64-e68.

Goyder, J. 1993. The Canadian syndrome of polarities: An obituary. Canadian Review of Sociology and Anthropology 30(1):1-12.

Health Canada. 1995. Canadians and Heart Health, Reducing the Risk. Catalogue no. H39-328/1995E. Ottawa: Minister of Supply and Services Canada.

Henripin, J. 2003. Les victoires contre la mort. In La métamorphose de la population canadienne, edited by J. Henripin, Montréal : Édition Varia, pp. 107-292.

Horiuchi S., N. Ouellette, S.L.K. Cheung, and J-M. Robine. 2013. Modal age at death: Lifespan indicator in the era of longevity extension. Vienna Yearbook of Population Research 11:37-69.

INSEE. 2010. Estimations de population et statistiques de l'état civil jusqu'en 2007 et projection de population 2007-2060. From N. Blanpain and O. Chardon. Projections de population à l'horizon 2060. INSEE Première (no. 1320, October).

Kannisto, V. 1994. Development of Oldest-Old Mortality, 1950-1990: Evidence from 28 Developed Countries. Odense: Odense University Press.

Kannisto, V. 2001. Mode and dispersion of the length of life. Population: An English Selection 13(1):159-71.

Katzmarzyk, P.T. 2002. The Canadian obesity epidemic, 1985-1998. Canadian Medical Association Journal 166(8):1039-40.

Katzmarzyk, P.T., and C.I. Ardern. 2004. Overweight and obesity mortality trends in Canada, 19852000. Canadian Journal of Public Health 95(1):16-20.

Lussier, M-H., R. Bourbeau, and R. Choinière. 2008. Does the recent evolution of Canadian mortality agree with the epidemiological transition theory? Demographic Research 18:531-68. 
Bourbeau and Ouellette: Trends, patterns, and differentials in Canadian mortality (1921-2011)

Mandich, S., and R. Margolis. 2014. Changes in disability-free life expectancy in Canada between 1994 and 2007. Canadian Studies in Population 41(1-2):192-208.

Manuel, D.G., and J. Hockin. 2000. Recent trends in provincial life expectancy. Canadian Journal of Public Health 91(2):118-19.

Martel, L., and A. Bélanger. 2006. An analysis of the change in dependence-free life expectancy in Canada between 1986 and 1996. Report on the Demographic Situation in Canada, 1998-1999. Catalogue no. 91-209-XPE. Ottawa: Statistics Canada.

Martel, S., and R. Bourbeau. 2003. Compression de la mortalité et rectangularisation de la courbe de survie au Québec au cours du XXe siècle. Cahiers québécois de démographie 32(1):43-75.

Matthews, R., and J.C. Davis. 1986. The comparative influence of regions, status, class, and ethnicity on Canadian attitudes and values, in Regionalism in Canada, edited by R.J. Brym. Toronto: Irwin, pp. $89-122$.

Meslé, F. 2004. Écart d'espérance de vie entre les sexes : les raisons du recul de l'avantage féminin. Revue d'épidémiologie et de santé publique 52(4):333-52.

- 2013. Will the gender gap in mortality continue to narrow? Paper presented at the Annual Meeting of the Population Association of America, New Orleans (April 11-13).

Meslé, F., and J. Vallin. 2000. Transition sanitaire : tendances et perspectives. Médecine-Science 16(11):1161-71.

Mustard, C.A., A. Bielecky, J. Etches, R. Wilkins, M. Tjepkema, B.C. Amick, P.M. Smith, W.H. Gnam, and K.J. Aronson. 2010. Suicide mortality by occupation in Canada, 1991-2001. Canadian Journal of Psychiatry 55(6):369-76.

Mustard, C.A., A. Bielecky, J. Etches, R. Wilkins, M. Tjepkema, B.C. Amick, P.M. Smith, and K.J. Aronson. 2013. Mortality following unemployment in Canada, 1991-2001. BMC Public Health 13:441-51.

Nagnur, D. 1986. Rectangularization of the survival curve and entropy: The Canadian experience, 1921-1981. Canadian Studies in Population 13:83-102.

Nagnur, D., and M. Nagrodski. 1990. Epidemiologic transition in the context of demographic change: The evolution of Canadian mortality pattern. Canadian Studies in Population 17(1):1-24.

Nault, F. 1997. Narrowing mortality gaps, 1978 to 1995. Health Reports 9(1):35-41.

Organisation for Economic Co-operation and Development (OECD) 2014. OECD Health Statistics 2014. Website: Public expenditure on health, \% total expenditure on health, TEH. http://stats.oecd. org/Index.aspx?DataSetCode=SHA

Office for National Statistics. 2013. Historic and projected mortality data from the period and cohort life tables, 2012-based, UK, 1981-2062. Statistical Bulletin (Dec).

Office of the Chief Actuary. 2012. 26th Actuarial Report on the Canada Pension Plan, as at 31 December 2012. Catalogue no. IN3-16/1-2012E-PDF. Ottawa.

Olshansky, J.S., and B.A. Ault. 1986. The fourth stage of the epidemiologic transition: The age of delayed degenerative diseases. The Milbank Quarterly 64(3):355-91. 
Olshansky, S.J., D.J. Passaro, R.C. Hershow, J. Layden, B.A. Carnes, J. Brody, L. Hayflick, R.N. Butler, D.B. Allison, and D.S. Ludwig. 2005. A potential decline in life expectancy in the United States in the 21st century. The New England Journal of Medicine 352(11):1138-42.

Omariba, W.R. 2015. Immigration, ethnicity, and avoidable mortality in Canada, 1991-2006. Ethnicity \& Health 20(4):409-36.

Omariba, D.W.R., E. Ng, and B. Vissandjée. 2014. Differences between immigrants at various durations of residence and host population in all-cause mortality, Canada 1991-2006. Population Studies 68(3):339-57.

Omran, A. 1971. The epidemiologic transition: A theory of the epidemiology of population change. The Milbank. Memorial Fund Quarterly 49(4):509-38.

Ouellette, N., M. Barbieri, and J.R. Wilmoth. 2014. Period-based mortality change: Turning points in trends since 1950. Population and Development Review 40(1):77-106.

Ouellette, N., and R. Bourbeau. 2011. Changes in the age at death distribution in four low mortality countries: A nonparametric approach. Demographic Research 25:595-628.

Ouellette, N., R. Bourbeau, and C.G. Camarda. 2012. Regional disparities in Canadian adult and oldage mortality: A comparative study based on smoothed mortality ratio surfaces and age-at-death distributions. Canadian Studies in Population 39(3-4):79-106.

Pampalon, R., D. Hamel, P. Gamache, and G. Raymond. 2009a. A deprivation index for health planning in Canada. Chronic Diseases in Canada 29(4):178-91.

Pampalon, R., D. Hamel, and P. Gamache. 2009b. A comparison of individual and area-based socioeconomic data for monitoring social inequalities in health. Health Reports 20(4):85-94.

Pampalon, R., D. Hamel, and P. Gamache. 2009c. Un indice de défavorisation pour la planification de la santé au Canada. Paper presented at the joint CIHI-INSPQ Workshop, Montreal (September 23).

Pampel, F.C. 2002. Cigarette use and the narrowing sex differential in mortality. Population and Development Review 28(1):77-104.

Pearl, R. 1923. Introduction to Medical Biometry and Statistics. Philadelphia: W.B. Saunders Co.

Peto, R., A.D. Lopez, J. Boreham, and M. Thun. 2005. Mortality from Smoking in Developed Countries 1950-2000. 2nd edn. Oxford: Oxford University Press.

PHAC (Public Health Agency of Canada). 2009. Tracking Heart Disease and Stroke in Canada (Cat. No. HP32- 3/2009E). Accessed via http://www.phac-aspc.gc.ca/publicat/2009/cvd-avc/pdf/cvdavs-2009-eng.pdf.

Preston, S.H., and H. Wang. 2006. Sex mortality differences in the United States: The role of cohort smoking patterns. Demography 43(4):631-46.

Preston, S.H., D.A. Glei, and J.R. Wilmoth. 2011. Contribution of smoking to international differences in life expectancy. In International Differences in Mortality at Older Ages: Dimensions and Sources, edited by E.M. Crimmins, S.H. Preston, and B. Cohen. Washington D.C.: National Academies Press, pp. 105-31.

Preston, S.H., A. Stokes, N.K. Mehta, and C. Bochen. 2014. Projecting the effect of changes in smoking and obesity on future life expectancy in the United States. Demography 51:27-49. 
Prud'homme, P. 2007. Évolution de la mortalité différentielle selon la province au Canada. Master's Thesis. Université de Montréal, Département de démographie.

Public Health Agency of Canada, and Canadian Institute for Health Information (PHAC-CIHI). 2011. Obesity in Canada. Ottawa.

Rau, R., C. Bohk, M.M. Muszynska, and J.W. Vaupel. 2013. Rates of mortality improvement on the Lexis surface: Visualizing age-, period-, and cohort-effects. Paper presented at the Annual Meeting of the Population Association of America, New Orleans (April 11-13).

Robine, J-M., and M. Allard. 1999. Jeanne Calment: Validation of the duration of her life, in Validation of Exceptional Longevity, edited by B. Jeune and J.W. Vaupel. Odense: Odense University Press, pp. $145-72$.

Roberge, R., J-M. Berthelot, and K. Cranswick. 1999. Adjusting life expectancy to account for disability in a population: A comparison of three techniques. Social Indicators Research 48:217-243.

Statistics Canada. 1981. The Health of Canadians: Report of the Canada Health Survey. Catalogue no. 82-538. Ottawa: Health and Welfare Canada/Statistics Canada.

1987. A review of National Health Surveys in Canada, 1878-1987. Report by the Working Group on Health Indicators. Ottawa: Health Division.

- 2012a. The Canadian Population in 2011: Age and Sex. Catalogue no. 98-311-X. Ottawa: Demography Division.

—. 2012b. Centenarians in Canada: Age and sex, 2011 Census. Catalogue no. 98-311-X2011003. Ottawa.

-2013a. Report on the Demographic Situation in Canada. Fertility: Overview, 2009 to 2011. Catalogue no. 91-209-X. Ottawa: Demography Division.

- 2013b. Life Tables, Canada, Provinces and Territories, 2009 to 2011. Catalogue no. 84-537-X - No. 005. Ottawa: Demography Division.

—. 2014a. Annual Demographic Estimates: Canada, Provinces and Territories. Catalogue no. 91-215-X. Ottawa: Demography Division.

- 2014b. Population Projections for Canada (2013 to 2063), Provinces and Territories (2013 to 2038). Catalogue no. 91-520-X. Ottawa: Demography Division.

Stewart, S.T., D.M. Cutler, and A.B. Rosen. 2009. Forecasting the effects of obesity and smoking on U.S. life expectancy. The New England Journal of Medicine 361:2252-60.

Sullivan, D. 1971. A single index of mortality and morbidity. HSMHA Health Reports 86:347-54.

Thatcher, A.R., V. Kannisto, and J.W. Vaupel. 1998. The Force of Mortality at Ages 80 to 120. Odense: Odense University Press.

Tjepkema, M., R. Wilkins, N. Goedhuis, and J. Pennock. 2012a. Cardiovascular disease mortality among First Nations people in Canada, 1991-2001. Chronic Diseases in Canada 32(4):200-07.

Tjepkema M., R. Wilkins, and L. Long. 2012b. Cause-specific mortality by education in Canada: A 16year follow-up study. Health Reports 23(3):3-11.

2013a. Cause-specific mortality by income adequacy in Canada: A 16-year follow-up study. Health Reports 24(7):14-22. 
2013b. Cause-specific mortality by occupational skill level in Canada: a 16-years follow-up study. Chronic Diseases and Injuries in Canada 33(4):219-30.

Tjepkema M., R. Wilkins, S. Senécal, É. Guimond, and C. Penney. 2009. Mortality of Métis and registered Indian adults in Canada: An 11-year follow-up study. Health Reports 20:31-51.

. 2010. Mortality of urban Aboriginal adults in Canada, 1991-2001. Chronic Diseases in Canada 31(1):5-25.

Trovato, F. 1985. Mortality differences among Canada's indigenous and foreign-born populations, 1951-1971. Canadian Studies in Population 12(1):49-80.

-1993. Mortality differences by nativity during 1985-87. Canadian Studies in Population 20(2):207-23.

- 2007. Narrowing sex differential in life expectancy in Canada. In The changing Face of Canada. Essential Readings in Population, edited by R. Beaujot and D. Kerr. Toronto: CSPI, pp. 127-40.

Trovato, F., and N.M. Lalu. 1995. The narrowing sex differential in mortality in Canada since 1971. Canadian Studies in Population 22(2):145-67.

- 2001. Narrowing sex differences in life expectancy: Regional variations, 1971-1991. Canadian Studies in Population 28(1):89-110.

Trovato, F., and N.B. Heyen. 2006. A varied pattern of change of the sex differential in survival in the G7 countries. Journal of Biosocial Science 38(3):391-401.

van Raalte, A.A., and H. Caswell. 2013. Perturbation analysis of indices of lifespan variability. Demography 50:1616-40.

Wadhera, S., and J. Strachan. 1993a. Selected Birth and Fertility Statistics, Canada, 1921-1990. Catalogue no. 82-553. Ottawa: Statistics Canada.

1993b. Selected Infant Mortality and Related Statistics, Canada, 1921-1990. Catalogue no. 82-549. Ottawa: Statistics Canada.

Waldron, I. 1993. Recent trends in sex mortality ratios for adults in developed countries. Social Science \& Medicine 36(4):451-62.

Wilkins, R. 1980. L'état de santé au Canada, 1926-1976. Montréal: Institut de recherches politiques.

Wilkins, R., and O. Adams. 1992. Les tendances de l'espérance de vie en santé au Canada, 1951-1986. In Espérances de santé, edited by J-M. Robine, M. Blanchet, and J.E. Dowd. Paris: INSERM.

Wilkins, R., M. Tjepkema, C. Mustard, and R. Choinière. 2008. The Canadian census mortality follow-up study, 1991 through 2001. Health Reports 19(3):27-48.

Wilmoth, J.R., L.J. Deegan, H. Lundström, and S. Horiuchi. 2000. Increase of maximum life-span in Sweden, 1861-1999. Science 289(5488):2366-68.

Wilmoth, J.R., and S. Horiuchi. 1999. Rectangularization revisited: Variability of age at death within human populations. Demography 36(4):475-95.

Yashin, A.I., A.S. Begun, S.I. Boiko, S.V. Ukrainseva, and J. Oeppen. 2001. The new trends in survival improvement require a revision of traditional gerontological concepts. Experimental Gerontology 37(1):157-67.

Zanfongnon, R. 2008. Évolution de la mortalité différentielle selon le sexe au Canada, 1921-2004 : variations régionales. Master's Thesis, Université de Montréal, Département de démographie. 
Bourbeau and Ouellette: Trends, patterns, and differentials in Canadian mortality (1921-2011)

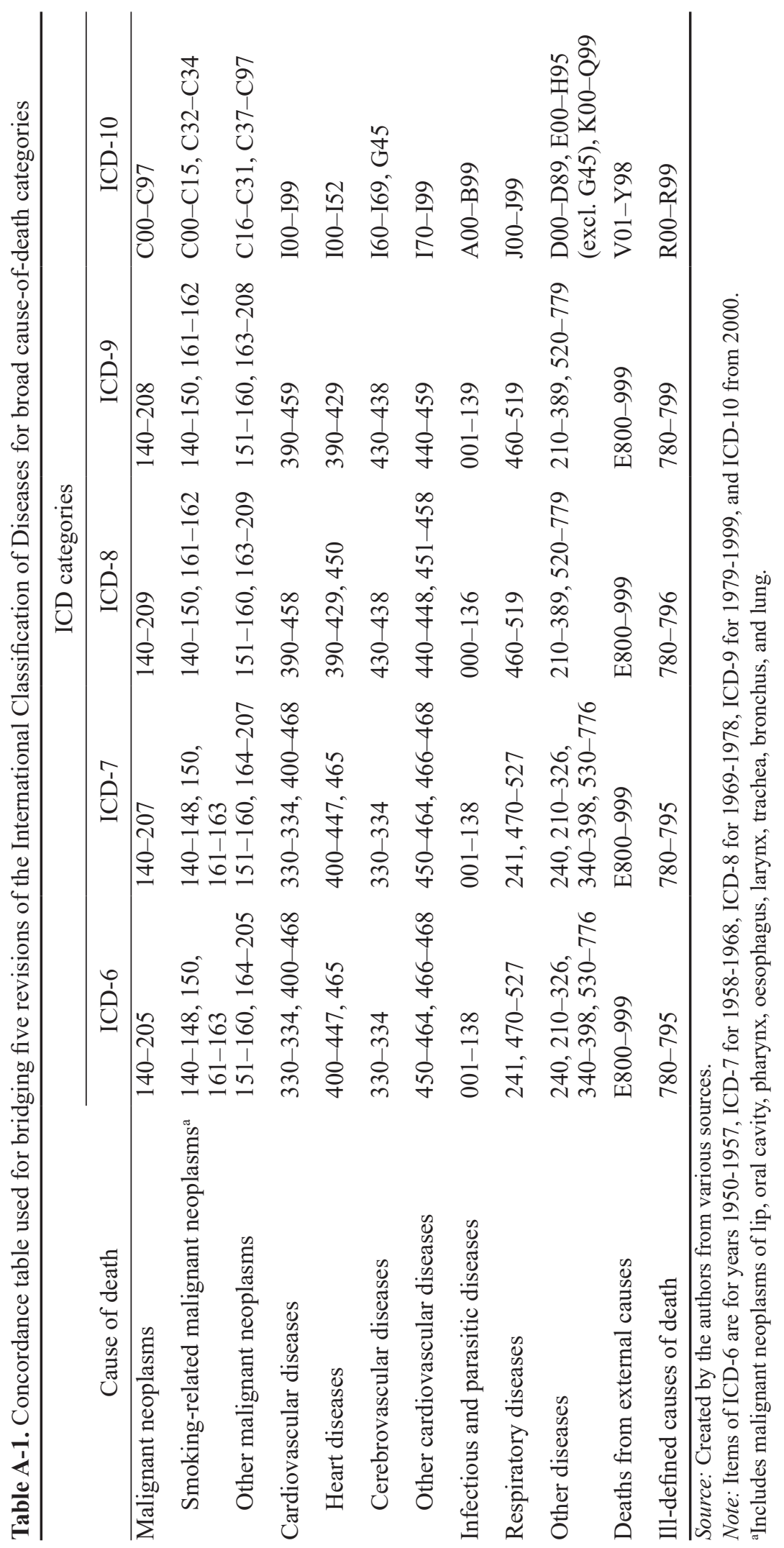

